Cornell University Law School

Scholarship@Cornell Law: A Digital Repository

$11-2016$

The Mechanisms of Derivatives Market Efficiency

Dan Awrey

Follow this and additional works at: https://scholarship.law.cornell.edu/facpub

Part of the Banking and Finance Law Commons, and the Securities Law Commons 


\title{
ARTICLES
}

\section{THE MECHANISMS OF DERIVATIVES MARKET EFFICIENCY}

\author{
DAN AwreY*
}

\begin{abstract}
These are not your parents' financial markets. A generation ago, the image of Wall Street was one of floor traders and stockbrokers, of opening bells and ticker symbols, of titans of industry and barbarians at the gate. These images reflected the prevailing view in which stock markets stood at the center of the financial universe. The high point of this equity-centric view coincided with the development of a significant body of empirical literature examining the efficient market hypothesis $(E M H):$ the prediction that prices within an efficient stock market will fully incorporate all available information. Over time, this equity-centric view became conflated with these empirical findings, transforming the EMH in the eyes of many observers from a testable prediction about how rapidly new information is incorporated into stock prices into a more general-and generally unexamined-statement about the efficiency of financial markets.
\end{abstract}

In their seminal 1984 article The Mechanisms of Market Efficiency, Ron Gilson and Reinier Kraakman advanced a causal framework for understanding how new information becomes incorporated into stock prices. Gilson and Kraakman's framework provided an institutional explanation for the empirical findings supporting the EMH. It has also played an influential role in public policy debates surrounding securities fraud litigation, mandatory disclosure requirements, and insider trading restrictions. Yet despite its enduring influence, there have been few serious attempts to extend Gilson and Kraakman's framework beyond the relatively narrow confines in which it was originally developed: the highly regulated, orderdriven, and extremely liquid markets for publicly traded stocks.

This Article examines the mechanisms of derivatives market efficiency. These mechanisms respond to information and other problems not generally encountered within conventional stock markets. These problems reflect important differences in the nature of derivatives contracts, the structure of the markets in which they trade, and the sources of market liquidity. Predictably, these problems have led to the emergence of very different mechanisms of market efficiency. This Article describes these problems and evaluates the likely effectiveness of the mechanisms of derivatives market efficiency. It then explores the implications of this evaluation in terms of the current policy debates around derivatives trade reporting and disclosure, the macroprudential surveillance of derivatives markets, the push toward mandatory

* Copyright (c) 2016 by Dan Awrey, Associate Professor of Law and Finance, University of Oxford. I would like to thank John Armour, Jo Braithwaite, Luca Enriques, Ron Gilson, Louise Gullifer, Bob Hockett, Kate Judge, Don Langevoort, Iain MacNeil, Saule Omarova, Georg Ringe, Peter Sørensen, Lynn Stout, Bob Thompson, Kristin van Zwieten, and Yesha Yadav for their extremely helpful comments and suggestions. This paper also benefited from the opportunity to present earlier drafts at the University of Oxford, Cornell University, National University of Singapore, and Copenhagen Business School. All errors remain my own. 
central clearing of derivatives, the prudential regulation of derivatives dealers, and the optimal balance between public and private ordering.

INTRODUCTION ..................................... 1105

I. Mechanisms of Market Efficiency: Gilson and

KraAkman's Framework and Its Influence ...... 1112

II. Why We Should Care About

Derivatives Market Efficiency................ 1122

III. Why Derivatives Are Different ................ 1124

A. The Nature of the Contracts................. 1125

B. The Structure of the Markets ................... 1132

C. The Sources of Market Liquidity ................ 1135

IV. The Mechanisms of Derivatives

MARket Efficiency . . . . . . . . . . . . . . . . . . . 1138

A. Dealers ................................. 1139

B. Interdealer Brokers and

Electronic Trading Platforms................. 1146

C. Netting and Collateral Regimes................ 1148

D. ISDA and Contractual Standardization ........... 1152

V. Policy Implications ........................... 1156

A. Derivatives Trade Reporting and Disclosure........ 1156

B. Macroprudential Surveillance

of Derivatives Markets ...................... 1162

C. Mandatory Central Clearing

of Standardized Derivatives .................... 1165

D. Prudential Regulation of Derivatives Dealers ........ 1169

E. The Optimal Balance Between

Private Ordering and Public Regulation............ 1174

Conclusion .......................................... 1179

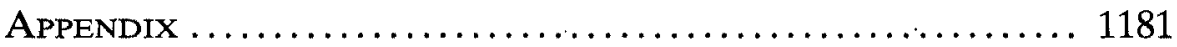

\section{INTRODUCTION}

These are not your parents' financial markets. A generation ago, the image of Wall Street was one of floor traders and stockbrokers, of opening bells and ticker symbols, of titans of industry and barbarians at the gate. ${ }^{1}$ These images reflected the prevailing view in which public equity markets-conventional stock markets-stood at the center of the financial universe. The high point of this equity-centric view coincided with the development of a significant body of empirical literature examining the efficient market hypothesis

1 These images were reinforced within popular culture by movies such as Oliver Stone's Wall STrEet and books such as Bryan Burrough and John Helyar's Barbarians at the Gate: The Fall of RJR Nabisco (1990). 
$(\mathrm{EMH})$ : the prediction that prices within an efficient stock market will fully incorporate all available information. ${ }^{2}$ Over time, this equitycentric view became conflated with these empirical findings, transforming the EMH in the eyes of many observers from a testable prediction about how rapidly new information is incorporated into stock prices into a more general-and generally unexamined-statement about the efficiency of financial markets. ${ }^{3}$

In their influential 1984 article The Mechanisms of Market Efficiency, ${ }^{4}$ Ron Gilson and Reinier Kraakman advanced a causal framework for understanding how new information becomes incorporated into stock prices. Gilson and Kraakman's framework was grounded in the observation that the efficiency of financial markets is a function of the market for information: how costly it is to acquire, process, and verify and, accordingly, its distribution within the marketplace. 5 For any initial distribution of information, Gilson and Kraakman then offered an account of how the trading activities of one or more types of traders served to ensure that this information ultimately found its way into prices. ${ }^{6}$ Amongst its many contributions, this framework provided a detailed institutional explanation for the empirical findings underpinning the EMH.

2 See infra Part I for a more detailed discussion of the EMH.

3 In the process, the benchmark of "efficiency" itself became prone to misunderstanding and abuse. Arguably nowhere was this more evident than in the context of the 1990s policy debates surrounding derivatives regulation and, specifically, the statements of former Federal Reserve Board Chairman Alan Greenspan. See, e.g., Alan Greenspan, Chairman, Fed. Reserve Bd., Remarks at the Financial Markets Conference of the Federal Reserve Bank of Atlanta (Feb. 21, 1997), https://www.federalreserve.gov/ boarddocs/speeches/1997/19970221.htm ("[T] he need for U.S. government regulation of derivatives instruments and markets should be carefully re-examined . . private market regulation appears to be achieving public policy objectives quite effectively and efficiently." (emphasis added)); Alan Greenspan, Chairman, Fed. Reserve Bd., Remarks at the Conference on Bank Structure and Competition of the Federal Reserve Bank of Chicago (May 1, 1997), https://www.federalreserve.gov/boarddocs/speeches/1997/19970501.htm ("The unbundling of financial products is now extensive throughout our financial system. Perhaps the most obvious example is the ever-expanding array of financial derivatives .... These and other developments facilitating the unbundling of financial products have surely improved the efficiency of our financial markets." (emphasis added)); see also The Regulation of OTC Derivatives: Hearing Before the H. Comm. on Banking and Fin. Servs., 105th Cong. (1998) (testimony of Alan Greenspan, Chairman, Federal Reserve Board), https://www.federalreserve.gov/boarddocs/testimony/1998/19980724.htm ("Inappropriate regulation distorts the efficiency of our market system and as a consequence impedes growth and improvement in standards of living.").

${ }^{4}$ Ronald J. Gilson \& Reinier H. Kraakman, The Mechanisms of Market Efficiency, 70 VA. L. Rev. 549 (1984).

5 Id. at 594-95 (describing taxonomy of information costs).

${ }^{6}$ See infra Part I for a more detailed description of Gilson and Kraakman's framework. 
Gilson and Kraakman's framework has gone on to play an influential role in public policy debates surrounding securities fraud litigation, mandatory disclosure requirements, and insider trading restrictions. ${ }^{7}$ It has also been used as a conceptual basis for understanding the economic role of securities underwriters, venture capital firms, auditors, credit rating agencies, and other "reputational intermediaries." Yet despite its enduring influence, relatively few scholars have attempted to extend this framework beyond the narrow confines in which it was originally developed: the highly regulated, order-driven, and extremely liquid markets for publicly traded stocks. ${ }^{8}$ This dearth of scholarship is especially puzzling given the Cambrian explosion of new financial markets, institutions, and instruments that has taken place since Gilson and Kraakman published their seminal article. Moreover, many of these new markets, institutions, and instruments bear little resemblance to the conventional stock markets at the heart of Gilson and Kraakman's original framework.

This paper examines the mechanisms of derivatives market efficiency. More specifically, it examines the mechanisms of market efficiency within bilateral or "over-the-counter" (OTC) derivatives markets. ${ }^{9}$ These markets include the $\$ 493$ trillion global markets for equity, credit, foreign exchange, interest rate, and other swaps. ${ }^{10}$ They also include the myriad of smaller and more exotic markets for swaps, options, and structured products based on physical commodities,

7 See infra Part I for a more detailed survey of this role.

${ }^{8}$ See infra Part IV for a survey of some of the literature examining the EMH in the context of fixed income and derivatives markets. Notably, Gilson and Kraakman have themselves extended their framework to fixed income markets. See Ronald J. Gilson \& Reinier Kraakman, Market Efficiency After the Financial Crisis: It's Still a Matter of Information Costs, 100 VA. L. REv. 313 (2014).

9 Accordingly, this Article does not directly examine the mechanisms of market efficiency within exchange-traded options or futures markets. However, as we shall see, a number of the mechanisms of OTC derivatives market efficiency-specifically contractual standardization, netting and collateral regimes, and clearinghouses-perform a functionally equivalent role within exchange-traded derivatives markets.

10 See Monetary \& Econ. Dep't, Bank for Int'l Setrlements, Statistical Release: OTC Derivatives Statistics at End-December 2015, at 2 (2016), http:// www.bis.org/publ/otc_hy1605.pdf. In its simplest form, a swap is a series of mutual forward obligations whereby two counterparties agree to periodically exchange cash flows over a specified period of time. Perhaps the most straightforward example is an interest rate swap pursuant to which one counterparty agrees to make payments at a fixed interest rate to another counterparty who in turn agrees to pay the borrower a variable (or "floating") rate. The fixed rate borrower receiving the floating rate thus stands to benefit from any subsequent increase in interest rates, whereas its counterparty receiving the fixed rate will benefit from any decline. The periodic payments due under a swap are calculated with reference to what is known as the "notional amount." The resulting obligations are then netted out against one another so that only one counterparty is required to make a payment in any given period. 
emissions rights, bandwidth, macroeconomic variables, the volatility of financial instruments or indices, and even Acts of God. These derivatives share three core features. ${ }^{11}$ First, unlike equity securities, derivatives are executory contracts that contemplate the performance of obligations by one or both traders over a potentially significant period of time. The introduction of time brings with it the prospect of counterparty default, making the identity of each trader highly relevant from a contracting perspective. This idiosyncratic counterparty credit risk also contributes to the economic and legal heterogeneity of many derivatives contracts. Second, derivatives markets have not historically benefited from institutional arrangements equivalent to conventional stock exchanges that serve to bring together prospective buyers and sellers, regulate the trading environment, or ensure the widespread dissemination of price, volume, and other trading information. Third, trading within derivatives markets instead revolves around a relatively small network of large financial intermediaries known as "dealers." These dealers quote prices to other traders on the basis that they are willing to take either side of a trade. Dealers thus represent the primary sources of liquidity within derivatives markets.

Together, these three core features of derivatives markets introduce information and other problems not generally encountered within conventional stock markets. These problems include the high initial costs of identifying potential traders willing to take the opposite side of a trade, along with the subsequent costs of engaging in both ex ante screening and ex post monitoring of their creditworthiness. They also include the costs of determining the prevailing market price in the absence of institutional arrangements designed to aggregate and disseminate prices and other trading information. Compounding matters, even if traders are able to observe market prices, idiosyncratic credit risk and the economic and legal heterogeneity of many derivatives makes it difficult for them to disentangle the constituent elements of price reflecting market, counterparty credit, and other risks. This heterogeneity introduces potentially significant price distortions, undermining the ability of traders to distill the informational signal embedded within any price changes from the noise generated by idiosyncratic counterparty credit risk and economic and legal heterogeneity. Finally, there are the information and agency problems stemming from the dealer-intermediated structure of derivatives markets, and the fact that liquidity within these markets is ultimately a

11 See infra Part III for a more detailed discussion of these features and how they serve to distinguish derivatives from public equity securities. 
function of the capacity and incentives of dealers to perform this important market-making role.

Predictably, these problems have led to the emergence of very different mechanisms of market efficiency than those identified by Gilson and Kraakman. ${ }^{12}$ The first mechanism consists of the small network of dealers at the center of global derivatives markets. These dealers use their client networks and relationships in order to identify and match traders looking to take the opposite sides of a trade. They also typically possess considerable expertise in screening and monitoring counterparty credit risk. Perhaps most importantly, however, by contractually interposing themselves between traders, dealers act as reputational intermediaries, using their status as repeat players to enhance the credibility of the commitments underpinning derivatives trades. This market-making role places dealers in an advantageous position to aggregate market information and, insofar as it is in their economic interest to do so, to share this information with other traders.

Dealers are supported in their market-making role by a second mechanism of market efficiency: interdealer brokers and electronic communication networks (ECNs). Interdealer brokers are intermediaries that act as conduits for the exchange of market information between dealers looking to enter into specific derivative trades, whether for the purposes of hedging existing exposures or engaging in proprietary trading. ECNs, meanwhile, enable dealers to communicate and trade directly with one another via dedicated webbased trading portals. Interdealer brokers and ECNs thus perform a role for dealers analogous to the one that dealers perform for their clients: aggregating market information and matching dealers looking to take the opposite sides of a trade. They can also act as informal channels for the dissemination of private trading information. In the process, interdealer brokers and ECNs can be viewed as lowering search costs within derivatives markets.

While the first two mechanisms of derivatives market efficiency can be viewed as extensions of Gilson and Kraakman's original framework, the final two mechanisms take us in an altogether different direction. The third mechanism consists of the highly specialized and intertwined contractual and legislative regimes governing the enforceability of closeout netting ${ }^{13}$ and the related treatment of financial collateral in the event of a derivative counterparty's default or

12 See infra Part IV for a more detailed examination of these mechanisms.

13 As described in greater detail in Section IV.C, closeout netting involves the termination, valuation, and netting out of contractual obligations in the event of counterparty default or insolvency. 
insolvency. Under certain conditions, these regimes can combine to render derivatives traders economically indifferent to the creditworthiness of their counterparties, thereby reducing the costs of counterparty screening and monitoring and eliminating idiosyncratic counterparty credit risk as a source of potential price distortions. The fourth mechanism, meanwhile, is embodied by the highly successful efforts of organizations such as the International Swaps and Derivatives Association (ISDA) in promoting greater contractual standardization within many derivatives markets. Like specialized netting and collateral regimes, the legal homogeneity generated by this standardization can be viewed as helping to eliminate potential price distortions.

Viewed together, these four mechanisms serve to highlight the two sides of every derivatives contract. For the purposes of this Article, the first-"bright"-side consists of an exposure to an underlying claim, whether it be an equity or debt security, loan, currency, commodity, or other asset or payoff. In the vast majority of cases, these claims will be sensitive to the revelation of new information, thus giving Gilson and Kraakman's original framework-updated to reflect a different institutional environment-analytical traction in understanding how new information becomes incorporated into derivatives prices. The second-"dark"-side consists of each trader's exposure to the default of its counterparty. Importantly, and in direct contrast with Gilson and Kraakman's mechanisms, the institutional arrangements used by counterparties to manage these exposures are designed to reduce the incentives of traders to acquire, process, and verify new price relevant information. ${ }^{14}$ Indeed, at least in theory, these arrangements act as substitutes for investments in new information. Ultimately, it is the tension between the mechanisms operating on bright and dark sides of derivatives markets that gives rise to many of the important analytical and policy problems examined in this Article.

As we shall see, each of the four mechanisms described in this Article holds the potential to make a significant contribution towards the efficiency of derivatives markets. By the same token, important questions remain regarding the effectiveness of these mechanisms and whether their prospective benefits outweigh the associated costs. The dealer-intermediated structure of derivatives markets makes it difficult for traders to observe the trading behavior of other market par-

14 In this respect, the Article shares a number of analytical parallels with the recent work of Kate Judge examining the importance of information, and "information gaps," in equity and money markets. Kathryn Judge, Information Gaps and Shadow Banking, 103 VA. L. REv. (forthcoming 2017). 
ticipants, thereby undermining efficiency-enhancing trade and price decoding. ${ }^{15}$ While we might expect dealers to share some of the trading information they acquire by virtue of their privileged market position, we would also expect them to fiercely protect the economic value of this information-ultimately at the expense of market efficiency. At the same time, specialized netting and collateral regimes and contractual standardization will only serve to eliminate counterparty credit risk and potential price distortions under a very narrow-and, in many cases, unrealistic-range of circumstances. Far from demonstrating their effectiveness, an examination of these mechanisms thus reveals the unique obstacles to market efficiency stemming from the nature of derivatives contracts and the structure of the markets in which they trade.

This examination of the mechanisms of derivatives market efficiency also raises a host of important and timely policy questions. The most important of these questions revolve around the post-crisis regulatory reforms introducing new derivatives trade reporting and disclosure requirements, enhancing macroprudential surveillance of derivatives markets, imposing mandatory central clearing on many standardized derivatives, and strengthening the prudential regulation of derivatives dealers. ${ }^{16}$ More broadly, this examination raises important questions about the optimal balance between public regulation and private ordering within derivatives markets.

This paper proceeds as follows. Part I begins with an overview of Gilson and Kraakman's original framework and briefly describes its influence, major criticisms, and enduring insights. Part II frames the motivation for this Article: identifying the principal reasons why we might care about derivatives market efficiency. Part III then describes why Gilson and Kraakman's framework does not offer a compelling account of the mechanisms of derivatives market efficiency, looking specifically at the nature of derivatives contracts, the structure of the markets in which they trade, and the sources of market liquidity. Part IV identifies and examines four mechanisms of derivatives market efficiency: dealers, interdealer brokers and ECNs, specialized netting and collateral regimes, and the ongoing efforts of ISDA to promote contractual standardization within derivatives markets. Part $V$ then explores some of the important policy implications that flow from this examination, with particular focus on the potential impact of post-

15 See infra Part $\mathbf{I}$ for a more detailed description of the mechanics and efficiency implications of trade and price decoding.

16 See infra Part $\mathrm{V}$ for a more detailed exploration of these policy questions. 
crisis regulatory reforms targeting derivatives markets and dealers on market efficiency.

This Article provides a detailed description of the institutional structure underpinning modern derivatives markets. It also yields a number of important policy insights. First, recent regulatory reforms designed to enhance the transparency of derivatives markets by introducing mandatory trade reporting and disclosure requirements may not have the desired impact on market efficiency. Simultaneously, however, the regulatory push toward mandatory central clearing of many standardized derivatives may have a previously underappreciated and salubrious impact on market efficiency by reducing idiosyncratic counterparty credit risk and economic and legal heterogeneity. Second, recent regulatory reforms designed to enhance the macroprudential surveillance of derivatives markets may not compel market participants to produce the type or granularity of information needed to successfully identify potential threats to financial stability. Third, new prudential requirements introduced in the wake of the financial crisis may serve to undercut the incentives of dealers to perform their important market-making role, thereby reducing market liquidity and, ultimately, efficiency. Given this prospect, it may be worthwhile to rethink the optimal balance between public and private ordering within derivatives markets with a view towards promoting the development of alternative market structures. Finally, and more broadly, this examination suggests that conventional wisdom about what works in securities laws may at best offer an incomplete framework for understanding the regulation of derivatives markets.

Mechanisms of Market EFficiency: Gilson and KRAAKMAN'S FramewORK AND ITS INFLUENCE

There are few concepts in financial economics that have attracted more attention-or controversy-than "market efficiency." 17 The concept of market efficiency is grounded in the Efficient Market Hypothesis or EMH. First articulated by Eugene Fama, the basic prediction at the heart of the EMH is that trading strategies based on available information will not yield risk-free profits within an efficient

17 For a synthesis of this controversy, as well as a useful survey of the empirical research testing the EMH, see Burton G. Malkiel, The Efficient Market Hypothesis and Its Critics, 17 J. ECon. Persp. 59 (2003). For a post-crisis update, see Burton G. Malkiel, The Efficient-Market Hypothesis and the Financial Crisis, in RETHINkIng THE FInANCIAL CRISIS 75 (Alan S. Blinder et al. eds., 2012). As Malkiel suggests, much of the controversy surrounding the EMH stems from a misunderstanding of its core predictions. Id. (arguing that "critics of EMH are using a far too restrictive interpretation of what EMH means"). 
market. ${ }^{18}$ Put simply, traders should not be able to beat the market by trading on information that is already available within the marketplace. This "no arbitrage" hypothesis is often reformulated into the statement that security prices in an efficient market will fully reflect all available information. ${ }^{19}$ An "efficient" market can thus be understood as one in which new information is rapidly incorporated into security prices.

Fama broke the EMH down into three sub-hypotheses. The "weak" form hypothesis predicts that all historical information will be incorporated into prices. ${ }^{20}$ The "semi-strong" form hypothesis, in contrast, predicts that all new and publicly available information will be incorporated into prices. ${ }^{21}$ Thus, for example, by the time a trader reads in The New York Times or Wired that Apple Inc. has announced the launch of its new Apple Watch, the semi-strong form hypothesis would predict that this information will already be reflected in the price of Apple's shares-thereby depriving the trader of any profitable trading opportunities. The "strong" form hypothesis then extends this prediction to all private information. ${ }^{22}$ It would thus predict that the expected impact of the Apple Watch on Apple's future cash flows will be reflected in its share price before the launch announcement, when only a small group of insiders are aware of its existence, product features, and other relevant information. As this example illustrates, these sub-hypotheses are ordered on the basis of the relative strength of their predictions: While the inability of a trader to extract profitable trading opportunities from historical information would seem unremarkable to all but the most devout technical analysts, the inability of a trader with material private information to profit from this advantage would seem very remarkable indeed. ${ }^{23}$ The EMH thus views a market in which private information fails to generate profitable trading opportunities as demonstrably more efficient than a market in which such opportunities continue to exist.

In 1978, economist Michael Jensen boldly stated that "there is no other proposition in economics which has more solid empirical evi-

18 Eugene F. Fama, Efficient Capital Markets: A Review of Theory and Empirical Work, 25 J. Fin. 383, 384-85 (1970).

19 Indeed, this is how Fama himself framed the EMH in the introduction to his seminal article. Id. at 383 (describing the ideal market as one in which "security prices at any time 'fully reflect' all available information").

$20 \mathrm{Id}$. at 388.

21 Id.

$22 I d$.

23 See Gilson \& Kraakman, supra note 4, at 558 (discussing the differences between the different forms of the Efficient Market Hypothesis). 
dence supporting it than the Efficient Market Hypothesis."24 Subsequent theoretical and empirical scholarship has put a significant dent in this claim. ${ }^{25}$ For the present purposes, however, the more important point is that, despite the general consensus amongst financial economists at the time, neither Fama nor any of his contemporaries put forward a compelling causal explanation for the observation that new information was rapidly incorporated into security prices. ${ }^{26}$ Indeed, it would fall to two legal scholars, Ron Gilson and Reinier Kraakman, to articulate a theoretical framework for understanding how information found its way into prices. This framework centered around what Gilson and Kraakman characterized as the "mechanisms of market efficiency."27

Gilson and Kraakman's framework rests on three fundamental building blocks. ${ }^{28}$ First, the availability of information for the purposes of the EMH is a function of the costs incurred by traders in order to acquire, process, and verify it. ${ }^{29}$ The higher these costs, the narrower the initial distribution of this information is likely to be within the marketplace, and the longer and potentially more circuitous the route this information must take before it becomes reflected in security prices. ${ }^{30}$ Hence, the efficiency of the market for informa-

24 Michael C. Jensen, Some Anomalous Evidence Regarding Market Efficiency, 6 J. Fin. ECON. 95, 95 (1978).

25 Indeed, there is now an enormous body of scholarship in the fields of economics, psychology, law, and other fields dedicated to the study of these and other anomalies. See, e.g., Roman Frydman \& Michael D. Goldberg, Beyond Mechanical Markets (2011) (describing "Imperfect Knowledge Economics" and how individuals' misinterpretations of the significance of economic fundamentals can impact the price of financial assets); Daniel Kahneman, Thinking, Fast and Slow (2011) (examining various cognitive biases in human decision making); RoBert J. SHILlER, IrRATIONAL EXUBERANCE (3d ed. 2015) (examining the structural, psychological, and cultural factors that can cause prices to diverge from economic fundamentals); ANDREI SHLEIFER, INEFFICIENT Markets: AN InTRoduction to Behavioral FinanCE (2000) (arguing that the assumptions of investor rationality and frictionless arbitrage underpinning the EMH are contradicted by institutional and psychological evidence).

26 See William H. Beaver, Market Efficiency, 56 Acct. Rev. 23, 23 (1981) ("The problem is not simply that concepts are difficult to test empirically, a pervasive phenomenon not unique to the efficient market literature, rather, the problem is that, at a conceptual level, prior to empirical testing, it is unclear what is meant by the term market efficiency.").

27 Gilson \& Kraakman, supra note 4, at 549.

28 As Gilson and Kraakman observe, these building blocks are in many respects clarifications or refinements of Fama's original framework. Id. at 558-59 (discussing Fama's tripartite classification of efficiency tests and finding that different information sets implicate their own processes of price formation and efficiency dynamics).

29 See id. at 594 (discussing types of information costs).

30 See id. at 558, 567, 593 (describing the interplay between the distribution of information and price). For a case study demonstrating how long and circuitous this route can be, see Robert P. Bartlett III, Inefficiencies in the Information Thicket: A Case Study of 
tion will have a direct impact on the efficiency of the market for capital. $^{31}$ Second, and as a consequence, a market that efficiently incorporates one piece of information into prices may not do so with respect to other pieces of information. ${ }^{32}$ How efficiently a market incorporates a new piece of information will instead be determined by the costs of acquiring, processing, and verifying that specific piece of information. Finally, the concept of market efficiency as envisioned by the EMH is based on an inherently relative benchmark: the speed with which new information is reflected in security prices. ${ }^{33}$ Accordingly, we must be careful to distinguish between the "informational" efficiency of a market as measured by the EMH and the "accuracy" of the prices observed within that market. ${ }^{34}$

Gilson and Kraakman use these building blocks to construct a causal framework for understanding an important puzzle at the core of the EMH: How do we square the empirical observations of Fama and others that public equity markets rapidly incorporate new information into prices with the fact that most information is not costlessly and instantaneously available within the marketplace? Put differently: How does information that may initially be available to only a very small number of traders become reflected in prices? Gilson and Kraakman's answer to this question revolves around four distinct

Derivative Disclosures During the Financial Crisis, 36 J. CoRp. L. 1 (2010). Bartlett's case study examines the share price of Ambac Financial, a mono-line insurance company that insured multi-sector collateralized debt obligations (CDOs). Id. at 2-4. Despite a considerable amount of publicly available information about Ambac's exposure to certain CDOs, news that these CDOs had experienced multiple notch credit rating downgrades was not reflected in Ambac's share price until they were "revealed" in subsequent quarterly earnings announcements. Id. at 6 . Bartlett attributes this inefficiency to the low salience of individual CDOs within Ambac's portfolio and the costs of processing CDO disclosures. Id. at 48.

31 See Gilson \& Kraakman, supra note 4, at 597 ("Our special interest in the information market's economizing process is its relationship to capital market efficiency.").

32 Id. at 559 ("An efficient market response to one information set does not necessarily mean that the market will respond efficiently to a different set."). As examined in greater detail in subsequent sections, the fact that a market can be relatively efficient with respect to one piece of information but not another has important implications in terms of the mechanisms of derivatives market efficiency.

33 Id. at 560 (defining "relative efficiency" as "a measure of the speed with which new information is reflected in price"). As Gilson and Kraakman observe, this maps squarely onto Fama's three sub-hypotheses. See id. at 608 fig.3. The difference between the strong, semi-strong, and weak form hypotheses is essentially the difference between markets that incorporate information before it becomes public, as soon as it becomes public, and at some--potentially long-point after it becomes public.

34 Indeed, this distinction has been a constant source of friction in academic debates around market efficiency. See, e.g., Jeffrey N. Gordon \& Lewis A. Kornhauser, Efficient Markets, Costly Information, and Securities Research, 60 N.Y.U. L. REV. 761, 761, 765 (1985) (observing that lawyers have often misunderstood this and other aspects of EMH). 
types of trading activity which, together, represent the mechanisms of market efficiency:

The first mechanism is "universally informed trading." 35 Universally informed trading includes trading that takes place on the basis of new information that is simultaneously disseminated to the entire marketplace. ${ }^{36}$ Writing over thirty years ago, Gilson and Kraakman gave as examples trading activity in response to news about the results of U.S. presidential elections or Federal Reserve policy announcements. ${ }^{37}$ Today, of course, new forms of electronic communication mean that there is a far greater volume of information that-technically at least-is costlessly and instantaneously available to the entire marketplace. Intuitively, then, the information that provides the basis for universally informed trading must also satisfy some sort of additional thresholds in terms of both its prominence within the universe of available information and, ultimately, its salience in terms of the pricing of the relevant security. ${ }^{38}$

The second and in many respects most important mechanism of market efficiency identified by Gilson and Kraakman is "professionally informed trading." 39 Even where information is widely available within the marketplace, traders may not all possess the same ability to effectively process it. Professionally informed trading is undertaken by firms and individuals who have made the human capital and other investments necessary to identify which pieces of information are relevant to the pricing of a given security, along with the likely impact of this information on its market price. ${ }^{40}$ These traders can include broker-dealers, research analysts, portfolio managers, and other institutional investors. Gilson and Kraakman see the defining characteristic of these professionally informed traders as being the comparative advantage they possess in terms of the production of "soft" 41 informa-

35 Gilson \& Kraakman, supra note 4, at 568.

$36 I d$. Universally informed trading also includes trading on the basis of historical information. See id. (noting that "old" information embedded in securities prices at minimum approximates the ideal of universal dissemination).

37 Id. at $568-69$.

38 Indeed, Gilson and Kraakman's examples of information that might provide the basis for universally informed trading activity suggest as much. See also Dan Awrey, Complexity, Innovation, and the Regulation of Modern Financial Markets, 2 HARv. Bus. L. REv. 235, 251-53 (discussing the "opacity" of financial instruments as a driver of complexity); Bartlett, supra note 30, at 54 (explaining that investor inattention may impair the processing of important but low salient information).

39 Gilson \& Kraakman, supra note 4, at 569.

$40 \mathrm{Id}$. at 569,594 (noting that "[e]valuation of information ... requires special skills, such as a facility in accounting, finance or securities analysis, that can ordinarily be obtained only through investment in expensive professional training").

41 See id. at 561. 
tion: forecasts, estimates, and other forward-looking information and analyses. ${ }^{42}$ This advantage means that such soft information may initially be distributed to a relatively small fraction of the marketplaceand perhaps even just a single trader. Nevertheless, where these traders account for a critical volume of trading activity, their trading activities can eventually result in the broader dissemination of this information within the marketplace and, thus, its incorporation into security prices. ${ }^{43}$ Importantly, however, because the requisite investments in expertise are themselves costly, professionally informed trading will only take place where traders expect to generate a profit from these investments. ${ }^{44}$

A question which logically flows from this is how the information possessed by professionally informed traders becomes incorporated into prices when these traders do not themselves account for a significant proportion of overall trading activity in a security. According to Gilson and Kraakman, the answer resides in a third mechanism of market efficiency: "derivatively informed trading." 45 Derivatively informed trading takes two forms. ${ }^{46}$ The first - "trade decoding" ${ }^{47}$ takes place when traders observe and mimic the trading activities of other traders perceived as enjoying superior information or expertise. ${ }^{48}$ Trading that takes place after an announcement that Warren Buffett has bought or sold an equity stake in a firm is thus an example

$42 I d$ at 569 (describing how a small group of informed traders cause prices to reflect semi-public information). Gilson and Kraakman's definition of "soft" information-which essentially focuses on whether the information is about the past or future, id. at 561 -is somewhat different from the one used elsewhere in the financial intermediation literature. This literature often defines "hard" information as being easily captured and transmitted in numerical form, in contrast with "soft" information, which is not. See, e.g., Mitchell A. Petersen, Information: Hard and Soft (July 2004) (unpublished manuscript), http:// www.kellogg.northwestern.edu/faculty/petersen/htm/papers/softhard.pdf.

43 As Gilson and Kraakman explain, "Subgroups of informed traders, or even a single knowledgeable trader with sufficient resources, can also cause prices to reflect information by persistent trading at a premium over 'uninformed' price levels." Gilson \& Kraakman, supra note 4 , at 570 .

44 See Paul G. Mahoney, Market Microstructure and Market Efficiency, 28 J. CoRP. L. 541,544 (2003) ("Clearly intermediaries must earn a return or they will not remain in the market.").

45 Gilson \& Kraakman, supra note 4, at 572.

46 This excludes direct, inadvertent revelation of information by professionally informed traders. Id. at 573. More recently, a new form of derivatively informed trading has emerged based on the analysis of order flow information (i.e., order flow decoding). Richard K. Lyons, New Perspective on FX Markets: Order-Flow Analysis, 4 INT'L FIN. 303, 303-04 (2001). The prevailing structure of derivatives markets makes order flow decoding more or less irrelevant for the present purposes.

47 Gilson \& Kraakman, supra note 4, at 573.

48 Id. at 574. 
of trade decoding. ${ }^{49}$ As this example illustrates, trade decoding relies on the identity of the traders, along with the details of their trading activity, as an indirect means of signaling information to the marketplace. The second form of derivatively informed trading-"price decoding"50 - takes place when traders observe and respond to anonymous price and other trading information. ${ }^{51}$ In contrast with trade decoding, price decoding does not demand that traders know the identity of other traders. What it does demand-perhaps heroically-is that traders successfully break down all the constituent elements of price in order to determine which price movements are driven by new information and which are driven by other (exogenous) factors. 52

Gilson and Kraakman's final mechanism of market efficiency is "uninformed trading." 53 The idea that uninformed traders can contribute to market efficiency may seem somewhat counterintuitive. Nevertheless, Gilson and Kraakman argue that in certain circumstances uninformed trading can generate aggregate forecasts that over the long term may be better than those of any single trader. ${ }^{54}$ As Gilson and Kraakman explain, "Although each trader's own forecasts are skewed by the unique constraints on his or her judgment, other traders will have offsetting constraints. As trading proceeds, the random biases of individual forecasts will cancel one another out, leaving price to reflect a single, best-informed aggregate forecast." 55

In effect, Gilson and Kraakman view these aggregate forecasts as a new and potentially valuable piece of information..$^{56}$ Inevitably, however, the value of this information rests on the assumption that biases in individual forecasts are indeed random and, thus, cancel each

49 See Gerald S. Martin \& John Puthenpurackal, Imitation is the Sincerest Form of Flattery: Warren Buffett and Berkshire Hathaway (Apr. 15, 2008) (unpublished manuscript), http://papers.ssrn.com/sol3/papers.cfm?abstract_id $=806246$ (documenting the market reaction to the news that Buffett had purchased a given security). Interestingly, Martin and Puthenpurackal find that the market does not fully incorporate these announcements into prices, with the effect that investments in portfolios which mimic Buffett's earn abnormal returns of $10.75 \%$ over the S\&P 500 Index. Id.

50 Gilson \& Kraakman, supra note 4, at 574.

$51 \mathrm{Id}$. at $574-75$.

52 See id. at 578 (attributing informed traders' ability to earn a return on information to other traders' inability to perfectly discern the cause of price movements); see also Sanford J. Grossman \& Joseph E. Stiglitz, On the Impossibility of Informationally Efficient Markets, 70 AM. ECON. REv. 393, 393-94 (1980) (describing the paradox of perfect price decoding, which would disincentivize information gathering, and proposing an alternate model in which uninformed traders are not perfect price decoders).

53 Gilson \& Kraakman, supra note 4, at 579.

$54 \mathrm{Id}$. at 580 .

55 Id. at 581 .

56 Id. at $580-81$. 
other out. ${ }^{57}$ Where the aggregate forecasts of uninformed traders remain biased, in contrast, the presence of uninformed traders in the marketplace may actually serve to impede the process by which new information becomes incorporated into prices. ${ }^{58}$

Together, Gilson and Kraakman regard these four mechanisms as performing distinct but ultimately complementary roles in promoting market efficiency. ${ }^{59}$ The precise combination of mechanisms will depend on the type of information in question and the extent of its initial distribution within the marketplace. Where information is widely available, universally informed trading will act to incorporate this information into prices. Where information is technically available but costly to process, meanwhile, or where it is initially available to only a narrow subset of traders, professionally informed trading will play an important role. ${ }^{60}$ Derivatively informed trading may then also act to ensure that this information becomes incorporated into prices. The net effect, according to Gilson and Kraakman, is that "[f]or any initial distribution of information in the market, including an initial distribution to no one in the case of optimal aggregate forecasts, one or more efficiency mechanisms facilitate the eventual 'reflection' of information into price." 61

Gilson and Kraakman's framework has gone on to play an influential role in the policy debates around the development of fraud-onthe-market theory under Securities and Exchange Commission (SEC) Rule $10 \mathrm{~b}-5,{ }^{62}$ the SEC's integrated disclosure and shelf prospectus regimes, ${ }^{63}$ insider trading restrictions, ${ }^{64}$ and the regulation of the

57 Gilson and Kraakman acknowledge that this is a demanding assumption. Id. at 584 .

$58 \mathrm{Id}$. Uninformed trading is the least developed and convincing of Gilson and Kraakman's four mechanisms, especially in light of the subsequent theoretical and empirical literature exploring various biases in human decision-making. See supra note 25 and accompanying text. However, as will become apparent, understanding the role of uninformed trading is largely irrelevant for the purposes of examining the mechanisms of derivatives market efficiency.

59 Gilson \& Kraakman, supra note 4, at 588-89.

60 Id. at 589 .

61 Id. at $588-89$.

62 See, e.g., Daniel R. Fischel, Efficient Capital Markets, the Crash, and the Fraud on the Market Theory, 74 CORNell. L. REv. 907, 911 (1989) (relying on Gilson and Kraakman's empirical evidence suggesting prices of actively traded securities reflect publicly available information); Jonathan R. Macey \& Geoffrey P. Miller, Good Finance, Bad Economics: An Analysis of the Fraud-on-the-Market Theory, 42 STAN. L. REv. 1059, 1083-91 (1990) (citing Gilson and Kraakman as evidence that previous price changes cannot be used to predict future changes).

63 See, e.g., Merritt B. Fox, Shelf Registration, Integrated Disclosure, and Underwriter Due Diligence: An Economic Analysis, 70 VA. L. Rev. 1005, 1007 (1984); Gordon \& Kornhauser, supra note 34 , at $810,818$.

64 See, e.g., Nicholas L. Georgakopoulos, Why Should Disclosure Rules Subsidize Informed Traders?, 16 INT'L REV. L. \& ECON. 417 (1996) (arguing that disclosure rules 
market for corporate control. ${ }^{65}$ Gilson, Kraakman, and others have also used this framework as a basis for examining the role of underwriters as "reputational intermediar[ies]"66 in the context of both initial public offerings and the marketing of new financial products. ${ }^{67}$ Subsequent scholarship has expanded on this concept to examine the economic functions of venture capital firms, ${ }^{68}$ auditors, ${ }^{69}$ and credit rating agencies. ${ }^{70}$ Indeed, Gilson and Kraakman's framework has even been used as a basis for exploring the mechanisms of market inefficiency. ${ }^{71}$

that make firm information free will improve market efficiency by assisting rationally informed traders and reducing irrational trading); Donald C. Langevoort, Investment Analysts and the Law of Insider Trading, 76 VA. L. REv. 1023, 1038 (1990) (noting that Gilson and Kraakman's "derivatively informed trading" improves market efficiency by allowing uninformed traders "to identify the insider as having an informational advantage and react accordingly").

65 See, e.g., Guhan Subramanian, The Drivers of Market Efficiency in Revlon Transactions, 28 J. CORP. L. 691, 693-98 (2003). Indeed, this impact has in many respects outlived that of the EMH. See William T. Allen, Securities Markets as Social Products: The Pretty Efficient Capital Markets Hypothesis, 28 J. CoRP. L. 551, 554-56 (2003) (stating that while the EMH no longer commands the confidence it once did, Gilson and Kraakman's work remains relevant for its foray into the institutional detail of securities markets).

66 Gilson \& Kraakman, supra note 4 , at 620 .

67 In the context of public offerings of equity securities, for example, Gilson and Kraakman view the status of underwriters as repeat players as enabling them to rent their reputations to issuers as a means of credibly signaling private information. $I d$. at $618-21$. See generally Randolph P. Beatty \& Jay R. Ritter, Investment Banking, Reputation, and the Underpricing of Initial Public Offerings, 15 J. FIN. ECoN. 213, 216-17 (1986); James R. Booth \& Richard L. Smith, II, Capital Raising, Underwriting and the Certification Hypothesis, 15 J. FIN. ECoN. 261 (1986). For a more skeptical perspective on the role of underwriters as reputational intermediaries, see Saul Levmore, Efficient Markets and Puzzling Intermediaries, 70 VA. L. Rev. 645, 657-59, 667 (1984). See generally Anita Indira Anand, The Efficiency of Direct Public Offerings, 7 J. SMALl \& EMERging Bus. L. 433 (2003) (arguing that corporations may under certain circumstances efficiently conduct direct public offerings without engaging an underwriter).

68 See Bernard S. Black \& Ronald J. Gilson, Venture Capital and the Structure of Capital Markets: Banks Versus Stock Markets, 47 J. Fin. Econ. 243, 254-55 (1998) (explaining how venture capital funds leverage their reputations to promote the success of the companies they finance).

69 See James D. Cox, The Oligopolistic Gatekeeper: The US Accounting Profession, in After Enron: Improving Corporate Law and Modernising Securities Regulation in Europe aNd the U.S. 295, 303-04, 304 n.22 (John Armour \& Joseph A. McCahery eds., 2006) (describing auditors' supervisory role and resultant responsibilities); Frank H. Easterbrook \& Daniel R. Fischel, Mandatory Disclosure and the Protection of Investors, $70 \mathrm{VA}$. L. REv. 669, 675 (1984) (stating that firms use outside auditors to "convince investors of their quality").

70 See John C. Coffee, Jr., The Ratings Agencies, in Gatekeepers: The Professions and Corporate Governance 283, 287-88 (2006) (remarking that the "reputational intermediary" model has long been the dominant view of the credit-rating process).

71 Lynn A. Stout, The Mechanisms of Market Inefficiency: An. Introduction to the New Finance, 28 J. CORP. L. 635, 638 (2003). 
As with any influential theory, Gilson and Kraakman's framework has also been subject to significant criticism. Alon Brav, J.B. Heaton, Lynn Stout, and others, for example, have argued that the framework's grounding in the EMH led Gilson and Kraakman to discount the potential impact of heterogeneous expectations, decisionmaking biases, and other behavioral "anomalies."72 Paul Mahoney has argued that the framework fails to account for how the institutional structure of the trading environment can promote or impede market efficiency. ${ }^{73}$ Allen Ferrell, meanwhile, has criticized the framework on the basis that it fails to provide a more precise account of how different mechanisms contribute to market efficiency. ${ }^{74}$ Other scholars have raised more fundamental questions about the effectiveness of Gilson and Kraakman's mechanisms. Jonathan Macey, for example, has observed that both business school students and journalists-not professionally informed traders-were the first to detect possible fraud at energy trading firm Enron. ${ }^{75}$ Bradford De Long, Andrei Shleifer, Lawrence Summers, and Robert Waldmann question whether professionally informed traders are likely to engage in informationally efficient arbitrage in the presence of significant levels of so-called "noise trading"76 -investment strategies based on beliefs, sentiments, and other irrational considerations not driven by new information. ${ }^{77}$

Despite these and other criticisms, Gilson and Kraakman's basic framework has endured as an example of the important insights that can potentially be gained by looking beyond securities prices as a benchmark of market efficiency and instead examining the institu-

72 See, e.g., Alon Brav \& J.B. Heaton, Market Indeterminacy, 28 J. Corp. L. 517, 518-20, 518 n.6 (2003); Stout, supra note 71, at 638, 649-50, 665-66.

${ }^{73}$ Mahoney, supra note 44. Notably, Mahoney identifies specialists and other market makers as a fifth mechanism of market efficiency which he labels "order flow informed price setting." Id. at 542. Mahoney's mechanism shares a number of similarities with the structurally informed traders described in Part IV.

74 Allen Ferrell, If We Understand the Mechanisms, Why Don't We Understand Their Output?, 28 J. CoRP. L. 503, 509-13 (2003) (examining why the financial economic models underpinning Gilson and Kraakman's framework possess such low explanatory power as measured by $\mathrm{R}^{2}$ ).

75 Jonathan R. Macey, A Pox on Both Your Houses: Enron, Sarbanes-Oxley and the Debate Concerning the Relative Efficacy of Mandatory Versus Enabling Rules, 81 WAsH. U. L.Q. 329, 336 (2003).

76 J. Bradford De Long et al., Noise Trader Risk in Financial Markets, 98 J. Pol. ECon. 703, 704-05 (1990) (presenting a model in which irrational noise traders affect prices).

77 See Fischer Black, Noise, 41 J. Fin. 529 (1986) (describing different types of "noise" and their potential impact on prices); Andrei Shleifer \& Lawrence H. Summers, The Noise Trader Approach to Finance, 4 J. ECON. PERSP. 19, 23-25 (1990) (reviewing what was then the emerging literature on the rationality and frictionless arbitrage assumptions underpinning the EMH). 
tional arrangements within which these prices are formed and adjust over time. ${ }^{78}$ It is in pursuit of this same objective that this Article employs and expands upon Gilson and Kraakman's framework to examine the mechanisms of derivatives market efficiency. However, before embarking on this examination, it is worth briefly identifying the principal reasons why we should care about the efficiency of derivatives markets.

\section{II \\ Why We Should Care About Derivatives MARKET EFFICIENCY}

There are a number of reasons why we might care about the efficiency of derivatives markets. Derivatives are bets on the direction of future price movements. ${ }^{79}$ Insofar as derivatives prices contain valuable information about traders' aggregate expectations regarding these future price movements, efficient derivatives markets can thus improve the efficiency of the underlying markets. ${ }^{80}$ Along a similar vein, derivatives are often utilized in order to create synthetic exposures to relatively illiquid assets such as corporate bonds and emerging market sovereign debt. They can also be used to create exposures to entirely artificial "assets" such as baskets of securities (e.g., the Markit $\mathrm{ABX}$ index) ${ }^{81}$ or financial indicators (e.g., the VIX index). ${ }^{82}$ In many cases, these derivatives markets may be deeper and more liquid than the relevant underlying markets - thus making deriv-

78 See Allen, supra note 65 , at 556-57 (advocating for a deeper institutional understanding of the mechanisms that support price formation).

79 Or, similarly, the probability that a specified future event will take place.

80 Consistent with this intuition, there is a body of empirical evidence suggesting that prices in options and futures markets often lead those of the underlying equity or debt markets. See, e.g., Fischer Black, Fact and Fantasy in Use of Options, 31 Fin. ANAlysts J. 36 (1975); Lawrence Harris, S\&P 500 Cash Stock Price Volatilities, 44 J. FIN. 1155, 1173 (1989); Stewart Mayhew et al., The Allocation of Informed Trading Across Related Markets: An Analysis of the Impact of Changes in Equity-Option Margin Requirements, 50 J. Fin. 1635 (1995); see also Haibin Zhu, An Empirical Comparison of Credit Spreads Between the Bond Market and the Credit Default Swap Market 13-14, 24-25 tbls.5 \& 6 (Bank for Int'l Settlements, Working Paper No. 160, 2004), http://www.bis.org/publ/ work $160 \mathrm{htm}$. Of course, the higher level of transparency in exchange-traded options and futures markets (relative to swap markets, for example) likely offers a more straightforward path for new derivatives price information to contribute to the price discovery process within underlying equity and debt markets. Viewed from this perspective, the recent regulatory reforms designed to improve swap market transparency described in Part V may serve to enhance price discovery in underlying markets.

81 The Markit $A B X$ index is a synthetic index whose value reflects a basket of twenty subprime mortgage-backed securities. $A B X$, IHS MARKIT, https://www.markit.com/ product/abx (last visited Sept. 2, 2016).

82. Created and administered by the Chicago Board Options Exchange, the VIX index is a measure of market participants' short-term volatility as reflected in the prices of S\&P 
atives markets an important part of the process by which new information becomes incorporated into asset prices.

The efficiency of derivatives markets can also play an important role in promoting-or impeding-effective investor protection. The faster new information is incorporated into prices, and the more widely these prices are disseminated, the smaller the window of opportunity will be for well-informed traders to exploit less knowledgeable market participants. Conversely, where markets are slow to absorb new information, this is likely to generate opportunities for well-informed traders to exploit their informational advantage. Insofar as the dispersion of information within the marketplace is random and unbiased, we might not view this as a particularly pressing problem: sometimes traders will win, sometimes they will lose. Where the prevailing market structure serves to entrench the informational advantage of a small number of traders, however, this state of affairs may raise legitimate concerns regarding the more systematic exploitation of less informed market participants.

The efficiency of derivatives markets has taken on even greater importance in light of recent regulatory proposals to supplement or altogether replace conventional capital requirements for banks with more market-based measures of credit risk based on derivatives prices. Oliver Hart and Luigi Zingales, for example, have proposed replacing capital requirements for systemically important banks with prudential requirements based on these banks' credit default swap (CDS) prices. ${ }^{83}$ Pursuant to this proposal, where CDS prices on a bank's junior debt increase beyond a specified threshold, the bank would be required to raise additional equity capital or be subject to other prudential constraints. The desirability of Hart and Zingales's proposal depends at least in part on how rapidly CDS markets incorporate new information regarding the creditworthiness of banks. The desirability of this and other similar proposals is examined in greater detail in Section V.E.

Finally, we might care about the efficiency of derivatives markets because financial policymakers do. Here, it is worth noting that the U.S. Congress has explicitly identified improving the process of "price discovery" 84 within derivatives markets as the primary rationale underpinning the introduction of the new trade reporting and disclo-

500 stock index options. CBOE Volatility Index (VIX), ChICAgo Boaro OptIons ExCHANGE, https://www.cboe.com/micro/vix/vixintro.aspx (last visited Sept. 2, 2016).

83 Oliver Hart \& Luigi Zingales, A New Capital Regulation for Large Financial Institutions, 13 AM. L. \& ECON. Rev. 453 (2011).

84 Distilled to its essence, price discovery is the process by which buyers and sellers determine the price of an asset in the marketplace. The process of price discovery includes 
sure requirements under Title VII of the Dodd-Frank Wall Street Reform and Consumer Protection Act. ${ }^{85}$ Accordingly, even if we disagree with the proposition that the efficiency of derivatives markets is important, examining the institutional arrangements that support the process by which new information is incorporated into derivatives prices can still provide us with useful insights into whether and to what extent policymakers are likely to achieve their stated objectives. The Dodd-Frank trade reporting and disclosure requirements, along with the important question of whether they are likely to improve price discovery within derivatives markets, are thus examined in greater detail in Section V.A.

All this is not to suggest that informational efficiency is the only yardstick against which the efficiency of derivatives markets can or should be evaluated. Far from it. Indeed, as will soon become apparent, an examination of the mechanisms of derivatives market efficiency also raises important questions about the accuracy of derivatives prices and, thus, the quality of the signal these prices send to both market participants and regulatory authorities. Moreover, as explored in greater detail in the next section, the "dark side" of derivatives markets fits uncomfortably within an analytical framework dedicated to understanding how new information becomes incorporated into prices. Nevertheless, approaching this examination from the perspective of informational efficiency offers some unique insights into the fundamental institutional differences between derivatives and equity markets and, accordingly, why conventional frameworks for thinking about the role of "securities" regulation-based on the dominant equity-centric view-are of limited utility when attempting to understand the challenges of regulating derivatives markets.

\section{III}

\section{Why Derivatives Are Different}

The theoretical and empirical literature examining the EMH revolves almost exclusively around the highly regulated, order-driven, and extremely liquid markets for publicly traded stocks. ${ }^{86}$ This same

the process by and speed with which information is absorbed by a market and incorporated into prices.

85 Dodd-Frank Wall Street Reform and Consumer Protection Act, Pub. L. No. 111-203, $\$ 727,124$ Stat. 1376, 1696 (2010) (amending the Commodity Exchange Act, 7 U.S.C. $\$ 2(\mathrm{a})$, to acknowledge that the purpose of the new trade reporting and disclosure rules is to "enhance price discovery").

${ }^{86}$ In a 2003 survey by Burton Malkiel, for example, fifty-one of fifty-five cited papers on the EMH examined its application within public equity markets. Malkiel, supra note 17, at 81-82. See infra Part IV for a survey of the relatively small body of scholarship focusing more specifically on the informational efficiency of derivatives markets. 
equity-centric view is reflected in both Gilson and Kraakman's original framework and the scope of its subsequent influence. ${ }^{87}$ Importantly, however, stock markets represent a relatively small fraction of the global stock of financial assets. As of June 2015, global public equity market capitalization stood at approximately $\$ 73.3$ trillion. ${ }^{88}$ While significant, this figure nevertheless renders public equity markets smaller than both the global markets for bonds, notes, and other fixed income debt securities ( $\$ 87.7$ trillion) ${ }^{89}$ and exchange-traded options and futures ( $\$ 63.4$ trillion). ${ }^{90}$ While apples-to-apples comparisons are difficult, this figure also pales in comparison to the $\$ 553$ trillion global swaps market. ${ }^{91}$

A detailed examination of the institutional arrangements supporting public equity and derivatives markets reveals a number of significant differences. The most important of these differences for the present purposes stem from the nature of the underlying contracts, the structure of the markets in which they trade, and the sources of market liquidity. This section examines these core differences, along with their important implications in terms of the information, agency, coordination, and other costs that traders in these markets are likely to encounter. Predictably, these costs have led to the emergence of very different mechanisms of derivatives market efficiency.

\section{A. The Nature of the Contracts}

The first important difference between equity and derivatives markets stems from the nature of the contracts that create these

87 Notably, Gilson and Kraakman did extend their framework into debt markets-and specifically the market for retail mortgage-backed securities (RMBS)-in a 2014 paper in response to the financial crisis. Gilson \& Kraakman, supra note 8, at 331-50. However, as we shall see, this extension did not seek to comprehensively examine the important differences between equity and fixed income markets.

88 Domestic Market Capitalization for June 2015, World Fed'N Exchanges, http:// www.world-exchanges.org/home/index.php/statistics/monthly-reports (last visited Sept. 2, 2016) (select "Domestic Market Capitalization" data series for June 2015).

89 Summary of Debt Securities Outstanding for $Q 4$ 2015, BANK FOR INT'L SETTLEMENTs, http://stats.bis.org/statx/srs/table/c1 (last visited Sept. 2, 2016).

90 Exchange Traded Futures and Options, by Location of Exchange for Q4 2015, BANK FOR INT'L SETTLEMENTs, http://stats.bis.org/statx/srs/table $/ \mathrm{d} 1 ? \mathrm{p}=20154 \& \mathrm{c}=$ (last visited Sept. 2, 2016).

91 Monetary \& Econ. Dep't, Bank for Int'l Settlements, OTC Derivatives STATISTICS AT END-JUNE 2015, at 2 (2015), http:/www.bis.org/publ/otc_hy1511.pdf. While the notional amount provides a conventional measure of the size of OTC derivatives markets, it does not capture the attendant risks. A more useful measure of size is "gross market value," which reflects the current exposures of counterparties under open contracts assuming that these contracts were all settled immediately. As of June 30, 2015, the Bank for International Settlements estimated the gross market value of all outstanding OTC derivatives at $\$ 15.5$ trillion. Id. 
instruments and that define the relationship between two traders on opposite sides of a trade. ${ }^{92}$ While these contracts vary in many important respects, ${ }^{93}$ there are two principal differences that stand out as being particularly relevant from an information cost perspective. The first is time. The transfer of legal ownership and economic risk from one trader to another within public equity markets takes place on the basis of something resembling a classical "spot" contract. ${ }^{94}$ The buyer promises to pay a price today in exchange for the delivery of a specific number of shares, and the seller promises to deliver the shares in exchange for payment. Viewed from this perspective, the transaction is thus not fundamentally dissimilar from the purchase of any number of other goods-an apple, say-which we make on a daily basis. Importantly, these contracts envision no contractual future beyond a very brief settlement period-typically no more than forty-eight to seventy-two hours after the trade is executed. ${ }^{95}$ The relationship between the buyer and seller is thus entirely extinguished within a matter of days, leaving the traders to go about their business completely unaffected by any subsequent changes in the creditworthiness of their erstwhile counterparty. As a result, the identity of the traders within public equity markets is essentially irrelevant from a contracting perspective. 96

In sharp contrast, one of the core features of derivatives is their status as "neoclassical" executory contracts that contemplate the performance of obligations by one or both traders over time. ${ }^{97}$ Under a typical swap contract, for example, both traders will owe contingent

92 Notably, in the case of equity securities, the contract creating the legal instrument is separate from the contract that facilitates its transfer from one trader to another. In the case of derivatives, in contrast, a single contract both creates the instrument and, conceptually at least, facilitates the "transfer" of economic risk.

93 Kate Judge, for example, has observed that the perpetual nature of equity securities means that their economic value can only be realized by selling them on a secondary market. Judge, supra note 14, at 9. As we shall see, derivatives markets are not characterized by the existence of the same type of secondary markets.

94 See Ian R. Macneil, The Many Futures of Contracts, 47 S. CAL. L. REv. 691, 720-21 (1974).

95 See, e.g., Press Release, Euronext, Introduction of $\mathbf{T}+2$ Standard Settlement Lifecycle (Jan. 14, 2014), http://www.nyxdata.com/nysedata/Default.aspx?tabID=993\&id= 2314 (announcing transition from a three-day to two-day settlement cycle). At the same time, any residual credit risk is effectively eliminated by virtue of the operation of the delivery-versus-payment settlement systems employed by stock exchanges.

96 See Oliver E. Williamson, Transaction-Cost Economics: The Governance of Contractual Relations, 22 J.L. \& ECON. 233, 236 (1979) (discussing the implications of Macneil's typology from a transaction cost perspective). This is not to suggest that the identity of the traders may not be relevant from a pricing perspective. As described in Part IV, the identity of a trader is very relevant indeed for the purposes of effective trade decoding.

97 See id. at 237-38 (describing the characteristics of such neoclassical contracts). 
obligations toward one another over a period that may span several years. Rather than contemplating the simple purchase of an apple at your local supermarket, these contracts are thus analogous to an enforceable obligation to continue to buy and sell apples at today's prices on a periodic basis for several years into the future. Importantly, the duration of these contracts introduces the risk that a trader may become insolvent or default between the moment of execution and the complete performance of its contractual obligations. The prospect of insolvency or default, in turn, makes the creditworthinessand thus the identity - of the traders highly relevant from a contracting perspective. Accordingly, while we might not care very much about the identity of the buyer when we sell 100 shares of Apple Inc. on the NASDAQ, we might care very deeply about the identity of the trader with whom we enter into a five-year total return swap for the purposes of taking a short position in the very same shares.

The second important difference in terms of the nature of the contracts is the degree of heterogeneity. Each common share of Apple Inc. is legally and economically identical. At the same time, stock exchanges such as the NASDAQ have historically provided a form of standardized private law governing, for example, issuer disclosure obligations, capital structure, governance, and the transfer of securities. ${ }^{98}$ While much of this private law has now been supplanted by public regulation, the effect has nevertheless been to inject a fairly high degree of standardization or homogeneity into both publicly traded shares and the legal and institutional environment in which they trade. ${ }^{99}$

Derivatives, in contrast, can exhibit a relatively high degree of economic and legal heterogeneity. From an economic standpoint, derivatives can be engineered by traders to create any conceivable combination of risk and return, from the price of Apple shares to the

98 See Jonathan R. Macey \& Maureen O'Hara, The Economics of Stock Exchange Listing Fees and Listing Requirements, 11 J. Fin. Intermediation 297, 299-300 (2002) (describing the evolution of the economic role of stock exchanges and their governance); Jonathan R. Macey \& Maureen O'Hara, Regulating Exchanges and Alternative Trading Systems: A Law and Economics Perspective, 28 J. Legal Stud. 17, 22 (1999) (describing the bundle of products provided by stock exchanges); Paul G. Mahoney, The Exchange as Regulator, 83 VA. L. REV. 1453, 1462 (1997) (expanding Gilson and Kraakman's analysis to include more detailed issues around equity market microstructure).

99 Notably, elements of this homogeneity-and specifically the institutional environment in which trading takes place-are in the process of being eroded by the emergence of alternative trading systems as important competitors to conventional stock exchanges. For an overview of these systems and their impact on the equity trading environment, see Merritt B. Fox et al., The New Stock Market: Sense and Nonsense, 65 DUKE L.J. 191 (2015) (analyzing the market effects of new equity trading practices and evaluating proposed reforms). 
price of apples. From a legal standpoint, the existence of idiosyncratic counterparty credit risk, differences in legal rules across jurisdictions, and the absence of coordination mechanisms equivalent to a stock exchange might be expected to lead to considerable divergence in terms of the underlying contractual architecture.

Crucially, this heterogeneity can even be observed in connection with the "purchase" and subsequent "sale" of a single derivative exposure by a single trader. Specifically, where the exposure-a long position in the shares of Apple, for example-is acquired under a derivatives contract with one counterparty subject to the laws of one jurisdiction, and later shifted under a contract with another counterparty subject to the laws of another jurisdiction, the trader will actually find itself a counterparty to two separate contracts, subject to the laws of two jurisdictions, and exposed to the default of two counterparties with potentially different credit risk profiles. The result is a complex and constantly changing web of market and counterparty exposures.

Time and heterogeneity have an important impact on the information costs encountered by derivatives traders. First, the duration of derivatives contracts-along with the corresponding exposure to counterparty default or insolvency-generate powerful incentives for traders to invest in ex ante screening in order to determine the creditworthiness of their prospective counterparties. It also incentivizes them to engage in ex post monitoring of their counterparties over the life of a derivatives contract. These investments in screening and monitoring can be very costly. The idiosyncratic nature of these investments means that they may also be largely non-recoverable (i.e., sunk). ${ }^{100}$ Intuitively, we might expect these investments to be particularly costly where the counterparties are large, complex financial institutions. This intuition finds support in the empirical research of Donald Morgan, who finds an unusual pattern of disagreement-or "splits"- between credit rating agencies over the ratings of banks and insurance firms. ${ }^{101}$ Morgan attributes this disagreement to the high costs of observing the quality of these firms' assets and the nature of their trading activities. ${ }^{102}$

100 See Williamson, supra note 96 , at $239-45$ (examining the role of transaction costs in determining the optimal governance structure - that is, markets or firms-in economic affairs).

101 Donald P. Morgan, Rating Banks: Risk and Uncertainty in an Opaque Industry, 92 Am. ECON. ReV. 874 (2002).

102 Id. at 874 (finding that bond-rating agencies disagree more if bank risk is harder to observe). 
Second, contractual heterogeneity means that it may be difficult to disentangle the stated price of a derivatives contract from its full economic price. In this context, the full economic price can be understood as incorporating any non-price terms that impose opportunity or other costs on contracting parties. An example may help illustrate this point. A derivatives dealer may quote Apple Inc. and Diana's Homemade Apple Pie Stand the same price on a five-year interest rate swap. Reflecting the significant difference in counterparty credit risk, however, the dealer may require Diana to post more or higher quality collateral as security against the performance of her future obligations. ${ }^{103}$ The dealer may also subject Diana to more intensive monitoring, or impose stricter contractual triggers governing, for example, the circumstances in which she will be required to post additional collateral in response to changes in interest rates or her own creditworthiness.

The imposition of these more burdensome contractual terms serves to increase the economic price of the contract from Diana's perspective, even though the stated price may be identical to that between the dealer and Apple Inc. Matters become even more complicated once we introduce the (perhaps more realistic) possibility that the dealer might initially quote Diana a higher stated price on the basis of its initial evaluation of her creditworthiness, or its expectations in terms of the volume of future business likely to be generated by this new relationship. Similarly, it may be possible for Diana to negotiate less onerous contractual terms in exchange for agreeing to an increase in the stated price, or by moving her savings account, commercial loans, or insurance to the dealer or its affiliates. ${ }^{104}$ At the same time, if Diana and Apple Inc. enter into contracts with the dealer at different times, differences in the stated price may reflect changes in the dealer's assessment of market risk and not the relative creditworthiness of its counterparties.

What this example illustrates is that-in the absence of relatively granular information about the identity of the counterparties, their broader relationship, creditworthiness, and economically important contractual terms-it can be difficult for traders to isolate whether observed changes in the market price of a derivatives contract are being driven by changes in market risk, counterparty credit risk, bargaining power, or other (potentially exogenous) factors. As depicted

103 These differences in contractual terms may also reflect relative differences in bargaining power between Diana and Apple Inc.

104 A dealer may especially be inclined to negotiate less onerous terms when this results in the dealer being able to secure more collateral against Diana's obligations under the swap. See infra Section IV.C (discussing collateral regimes). 
in Figure 1, the full economic price of a derivatives contract is thus analogous to an iceberg, with a number of potentially significant pricing variables hidden or distorted beneath the surface.

\section{Figure 1}

$\left.\begin{array}{|c|}\hline \text { Stated Price } \\ \hline \text { Counterparty Credit Risk } \\ \hline \text { Amount of Collateralization } \\ \hline \text { Quality of Collateral } \\ \hline \text { Collateral Triggers } \\ \hline \text { Formal Monitoring } \\ \hline \text { Other Economically Important } \\ \text { Contractual Terms } \\ \hline \text { Broader Relationship } \\ \text { Between Counterparties } \\ \hline\end{array}\right]$ The "Dark Side"

Figure 1 also helps demarcate the boundary between the "bright" and "dark" sides of a derivatives contract. The bright side consists of an exposure to changes in the value of an underlying asset, or the probability of an expected future payoff. This exposure is commonly referred to as "market risk." In many cases, the price of this underlying asset-shares in Apple Inc., for example ${ }^{105}$-will be sensitive to the revelation of new information. As a corollary, we would expect any new information to also eventually find its way into the price of derivatives contracts that create an exposure to this underlying. Indeed, as we shall see, this information may even be incorporated into derivatives prices before it is reflected in the price of the underlying. ${ }^{106}$ Where this is the case, we would expect the stated price of executed trades to signal potentially valuable information to the marketplace about traders' expectations regarding future price movements, thereby theoretically opening the door for efficiency-enhancing

105 While equity securities offer a relatively straightforward example for the present purposes, there remains an important question concerning how far we can extend this to other asset classes. This question is examined in greater detail in Part IV.

106 See infra notes 135-37 and accompanying text (citing studies concluding that derivatives markets and prices exhibit fluctuations reflecting reactions to new information earlier than corresponding anticipatory or reactionary shifts in stock prices, bond prices, and credit rating announcements). 
trade and price decoding. Importantly, the fact that information regarding recently executed trades is likely to be relevant to the price of both subsequent derivatives contracts and the underlying means that conventional regulatory strategies such as post-trade transparency may serve to enhance informational efficiency. ${ }^{107}$

The dark side of a derivatives contract consists of the exposure of each trader to the default or insolvency of its counterparty. As described in greater detail in Section IV.C, traders employ a number of mechanisms to manage this idiosyncratic counterparty credit risk. The most important of these mechanisms include closeout netting and the posting of financial collateral. As we shall see, these mechanisms are theoretically designed to act as substitutes for investments by traders in new information about the creditworthiness of their counterparties, thus leaving them in what Bengt Holmstrom has characterized as a "blissful state of 'symmetric ignorance." "108 Importantly, the role of these mechanisms in creating an equilibrium in which mutual ignorance can be used to overcome potential adverse selection problems does not fit squarely within Gilson and Kraakman's framework. The centrality of these mechanisms to the operation of derivatives markets also calls into question the likely effectiveness of conventional regulatory strategies as a means of enhancing informational efficiency. ${ }^{209}$

The bundling of market and idiosyncratic counterparty credit risk within a derivatives contract has potentially significant implications in terms of the informational content of derivatives prices. Perhaps most importantly, despite its clear economic importance, the dark side of a derivatives contract may or may not be reflected in the stated price. As a result, stated prices may send a potentially ambiguous-or "noisy"-signal to other traders. Amongst other implications, this noise adds to the already significant obstacles to efficiency-enhancing trade and price decoding, thus rendering such decoding costlier, and ultimately less likely, within derivatives markets.

As described in greater detail in Part IV, the information costs generated by time and economic and legal heterogeneity can ulti-

107 See Judge, supra note 14, at 15-17 (discussing the use of share-price information). The potential impact of these strategies is examined in greater detail in Section V.A.

108 Bengt Holmstrom, Understanding the Role of Debt in the Financial System 6 (Bank for Int'l Settlements, Working Paper No. 479, 2015), http://www.bis.org/publ/work479.htm; see also Judge, supra note 14, at 12 (discussing Holmstrom's view on the opacity of money markets). While Holmstrom was writing in relation to money markets, the dynamics of the operation of closeout netting and financial collateral very much mirror those of money, and specifically, repo markets.

109 For an excellent discussion of the limits of conventional securities law strategies in the context of banking and money markets, see Judge, supra note 14. 
mately help us better understand the role of dealers as reputational intermediaries within derivatives markets, along with the role played by organizations such as ISDA in promoting greater contractual standardization. These costs can also help us understand the drivers behind the development of specialized netting and collateral mechanisms that, by minimizing the exposure of traders in the event of counterparty default, serve as potential substitutes for investments in counterparty screening and monitoring. At the same time, the observation that derivatives contracts consist of both a bright and dark side serves to distinguish them from publicly traded stocks. This difference exposes the limits of Gilson and Kraakman's framework and raises a host of important and largely unanswered questions about the optimal role of regulation within derivatives markets.

\section{B. The Structure of the Markets}

The second important difference between equity securities and derivatives relates to the structure of the markets in which they trade. Historically, the vast majority of trading within public equity markets has taken place on order-driven exchanges such as the New York, London, or Tokyo Stock Exchanges. In recent years, a significant fraction of trading has also taken place on so-called "alternative" trading platforms such as BATS, Turquoise, and Chi-X. ${ }^{110}$ Exchanges and alternative trading platforms perform an important role in the aggregation and dissemination of information about the prevailing "bid" and "asking" prices for different equity securities, 111 along with the publication of information about the price and volume of executed trades. NASDAQ's public website, for example, provides real time information about the best available bid and asking prices for shares of Apple Inc., in addition to price and volume information for individual trades. ${ }^{112}$

Exchanges and alternative trading platforms also play an important role in establishing the rules pursuant to which these trades take place. Stock exchanges, for example, typically impose order-matching and trade-pricing rules. Order-matching rules ensure that the best

110 As of 2013, the U.S. Securities and Exchange Commission estimated that $11.31 \%$ (by dollar volume) and $12.12 \%$ (by share volume) of trading in U.S. public equities had migrated to such alternative trading platforms. Laura Tuttle, Alternative Trading Systems: Description of ATS Trading in National Market System Stocks 2 (SEC Div. of Econ. \& Risk Analysis, White Paper, Oct. 2013), http://www.sec.gov/marketstructure/research/alter native-trading-systems-march-2014.pdf.

111 The "bid" price represents the maximum price that a buyer is willing to pay for an asset. The "ask" price represents the minimum price at which a seller is willing to sell it.

112 NASDAQ Last Sale (NLS) Intraday Trade History: Apple Inc. (AAPL), NASDAQ, $\mathrm{http}: / / \mathrm{www}$.nasdaq.com/symbol/aapl/time-sales (last visited Sept. 2, 2016). 
(highest) bid is matched with the best (lowest) asking price, thereby incentivizing both buyers and sellers to submit competitive orders and ensuring that no traders receive preferential treatment. ${ }^{113}$ Tradepricing rules then determine the price at which the resulting trades are executed, cleared, and settled. ${ }^{114}$ Exchanges and alternative trading platforms can thus be viewed as valuable coordination mechanisms, aggregating and disseminating information about security prices and other trading information, bringing together buyers and sellers in the marketplace, and providing a common legal and institutional environment for trading in equity securities.

One of the defining characteristics of derivatives markets, in contrast, has historically been the absence of a coordination mechanism equivalent to an exchange or alternative trading platform. Unlike equity markets, there is no publicly available source where Diana of the eponymous apple pie stand, for example, could go to find the current bid and asking prices for a five-year interest rate swap, or information regarding recently executed trades. In theory, Diana would therefore need to somehow construct her own dataset of historical prices. She would also need to interact with a number of other traders in order to aggregate information about the range of current bid and asking prices. Compounding matters, in the absence of a market structure that brought together prospective buyers and sellers, Diana would need to take it upon herself to identify other traders willing to take the opposite side of the trade. Depending on how idiosyncratic her needs were in terms of the denominated currency of the swap, its duration, and other features, the costs of identifying these traders could be very significant. Viewed in isolation, then, the absence of an exchange or equivalent coordination mechanism can be seen as increasing the search and other information costs for Diana and other traders within derivatives markets.

Public equity markets provide a useful benchmark against which to compare the information and other costs that traders are likely to encounter within derivatives markets. At the same time, this comparison risks giving the misleading impression that derivatives markets are somehow completely unstructured. In practice, derivatives markets are loosely organized around a relatively small group of large traders known as "dealers." Prominent derivatives dealers include Citigroup, JP Morgan, Goldman Sachs, Deutsche Bank, and HSBC. More recently, large asset managers such as BlackRock have also

113 See Larry Harris, Trading and Exchanges: Market Microstructure for Practitioners 116-20 (2003) (describing rule-based order-matching systems).

114 See id. at 120 (describing the three most common trade-pricing rules). 
started acting as derivatives dealers. ${ }^{115}$ These dealers quote bid and asking prices to other traders on the basis that they are willing to take either side of the contemplated trade. ${ }^{116}$ For example, JP Morgan might quote Diana a bid of $5.00 \%$ and an ask of $5.05 \%$ on the fixed leg of a five-year U.S. dollar interest rate swap. In this example, the bid represents the gross interest rate Diana would receive if she were to elect to take the fixed leg of the swap, and the ask represents the rate she would pay if she were to take the variable or "floating" leg. ${ }^{117}$ Dealers will then typically look to hedge their exposures under the resulting trade by seeking out and entering into one or more offsetting swaps with other traders or, in many cases, other dealers. In theory at least, dealers thus attempt to profit not by placing bets on the future direction of prices, but by charging a fee-typically embedded in the spread between the quoted bid (e.g., 5.00\%) and asking (e.g., 5.05\%) prices-for their willingness to stand on the opposite side of the trade. Where permitted, of course, dealers may also enter into proprietary trades on the basis of their expectations regarding future price movements.

The important role played by dealers in reducing search and other information costs within derivatives markets is examined in greater detail in Part V. At the same time, the dealer-intermediated structure of derivatives markets is also the source of potentially significant costs. Perhaps most importantly, the absence of a mechanism for aggregating and publicly disseminating prices and other trading information has historically presented a significant obstacle for traders such as Diana's Homemade Apple Pie Stand seeking to determine the best available price. ${ }^{118}$ The resulting market opacity puts dealers in an advantageous informational position vis-à-vis other market participants, theoretically enabling them to exploit their less informed clients. ${ }^{119}$ The prospect of exploitation is magnified insofar as dealers are

115 See Dan McCrum \& Michael Mackenzie, BlackRock Looks to Take On Wall Street, Fin. Trmes (Apr. 12, 2012, 6:50 PM), http://www.ft.com/cms/s/0/4112b7dc-84b0-11e1-a3c500144feab49a.html.

116 See Dan Awrey, The Limits of Private Ordering Within Modern Financial Markets, 34 Rev. BANKING \& FIN. L. 183, 202 (2014-2015) (describing the role of dealers in making markets in OTC derivatives). These quotes can take the form of either binding or indicative (non-binding) quotes.

117 In this example, the floating leg would typically be fixed at a benchmark rate (for example, Libor) plus a specified number of percentage (or "basis") points (for example, $+2.0 \%)$.

118 To drive home this point, compare the ease with which it is possible to find the current price of Apple shares using a simple online search with the difficulty of obtaining similar publicly available information from a total return swap on these shares.

119 For a theoretical framework for understanding how the opaque, dealerintermediated markets can generate opportunities for exploitation, see Albert S. Kyle, 
compelled to make idiosyncratic, relationship-specific investments in understanding their clients' business and evaluating counterparty credit risk. ${ }^{120}$ These investments can be viewed as giving incumbent dealers (who already have a relationship with a client) a comparative informational advantage over potential competitors (who would theoretically need to factor these investments into their quoted prices), thereby undermining vigorous price competition.

\section{The Sources of Market Liquidity}

The divergent structures of public equity and derivatives markets expose a third important difference: the sources of market liquidity. The concept of liquidity is extremely abstract and, thus, difficult to define with any real precision. ${ }^{221}$ At a very basic level, however, liquidity can be understood as measuring a trader's ability to execute a trade rapidly and with minimal price impact. ${ }^{122}$ It is thus a function of both the amount of time it takes to buy or sell a security and the effect of the trade on that security's price. Conventional measures of market liquidity include the number (or "depth") of buyers and sellers in the marketplace, the number (or "volume") of executed trades, and the size of prevailing spreads between bid and asking prices. ${ }^{123}$

Stock exchanges promote market liquidity in two primary ways. ${ }^{124}$ First, the very existence of an exchange can be understood as

Continuous Auctions and Insider Trading, 53 Econometrica 1315 (1985). For a sense of some of the ways in which this exploitation might manifest itself in practice, see, for example, the UK Financial Conduct Authority's recent review uncovering widespread misselling of certain interest rate derivatives. Interest Rate Hedging Products (IRHP), Fin. Conduct Auth. (June 11, 2016), http://www.fca.org.uk/consumers/financial-servicesproducts/banking/interest-rate-hedging-products (last visited Aug. 22, 2016).

120 Relationship-specific investments can be understood as investments of time, effort, or other resources, the payoffs from which depend on the continuation of a given relationship. See Vincent P. Crawford, Relationship-Specific Investment, 105 Q.J. ECON. 561, 561 (1990) (defining relationship-specific investment as an investment whose returns depend on the relationship's continuation).

121 See Sanford J. Grossman \& Merton H. Miller, Liquidity and Market Structure, $43 \mathrm{~J}$ FIN. 617, 617 (1988) (demonstrating the difficulty of defining liquidity in precise mathematical terms).

122 Markus Brunnermeier and Lasse Pedersen refer to this type of liquidity, which essentially measures the ease with which a financial instrument can be traded, as "market liquidity." Markus K. Brunnermeier \& Lasse Heje Pedersen, Market Liquidity and Funding Liquidity, 22 REV. FIN. STUD. 2201, 2201 (2009) (defining market liquidity).

123 Tarun Chordia et al., Market Liquidity and Trading Activity, 56 J. FIN. 501, 502 (2001).

124 See HARRIS, supra note 113 (describing the microstructure of public equity markets); Daniel R. Fischel \& Sanford J. Grossman, Customer Protection in Futures and Securities Markets, 4 J. Futures Mkrs. 273 (1984) (examining the private rules and institutions that have evolved to protect customers in public equity and futures markets); J. Harold Mulherin et al., Prices are Property: The Organization of Financial Exchanges from a 
an important source of market liquidity. The aggregation and dissemination of trading information, combined with the production of rules governing the trading environment, serve to reduce information costs for traders and ameliorate potential adverse selection and agency problems. The amelioration of adverse selection and agency problems increases the confidence of traders in the integrity of the marketplace, thereby attracting buyers and sellers and increasing the depth and volume of trade. Greater depth and volume of trading activity then serves to enhance the process of price discovery, resulting in narrower spreads between bid and asking prices. ${ }^{125}$ More traders, executing more trades, at narrower bid-ask spreads can then be understood as generating greater market liquidity. Greater liquidity, in turn, attracts more market participants-increasing the depth and volume of trade, enhancing price discovery, reducing spreads, and generating still greater liquidity. ${ }^{126}$

Secondly, stock exchanges also utilize more bespoke mechanisms to promote market liquidity. ${ }^{127}$ For example, many exchanges use call market auctions at the start of a trading session or following a halt in trading. Rather than matching orders as they are entered, call markets allow for the accumulation of buy and sell orders for a specified period of time before they are matched, priced, executed, cleared, and settled. ${ }^{128} \mathrm{By}$ allowing order flow to build up in this way, call markets can be understood as aggregating market liquidity. For this reason, some exchanges also use call markets for trading in thinly traded stocks. ${ }^{129}$ Along a similar vein, many exchanges impose an affirmative obligation on designated exchange members-historically referred to as "specialists"130_to maintain fair and orderly markets in specific securities. These specialists use their own balance sheets to intervene in the marketplace during periods of illiquidity, buying where there is

Transaction Cost Perspective, 34 J.L. \& Econ. 591 (1991) (examining the evolution of private rules governing U.S. stock exchanges).

125 See Mulherin et al,, supra note 124, at 593-94 (describing how exchanges alleviate the costs of price discovery).

126 For this reason, it is often said that "liquidity begets liquidity." See THIERRY Foucault et al., Market Liquidity: Theory, Evidence, and Policy 310 (2013).

127 HARRIS, supra note 113.

128 See id. at 91 (discussing the mechanics of call markets).

129 Id.

130 Notably, the lexicon of equity market making is changing in this regard. The New York Stock Exchange (NYSE), for example, has recently replaced "specialists" with Designated Market Makers (DMMs). Like specialists, DMMs have an affirmative obligation to maintain fair and orderly markets in their designated securities. The NYSE has also recently introduced a new category of market maker known as Supplemental Liquidity Providers (SLPs). SLPs receive financial incentives from the NYSE in exchange for creating liquidity in their designated securities. Market Model, NYSE, https:// www.nyse.com/market-model/overview (last visited July 2, 2016). 
a scarcity of demand (bids), and selling where there is a scarcity of supply (asks). ${ }^{131}$ Exchanges can thus be viewed as important sources of market liquidity. Importantly, this liquidity exists independently of the traders that collectively make up the marketplace. As a result, we would not generally expect the failure of one or more important traders-or their unwillingness to trade-to have a significant impact on market liquidity.

The sources of liquidity within derivatives markets are the largest and most important market participants: dealers. As of June 2010, the fourteen largest derivatives dealers-the so-called "G14"-were counterparties to swaps representing approximately $82 \%$ of the global notional amount outstanding. ${ }^{132}$ Given this concentration of trading activity, liquidity within derivatives markets is essentially a function of the capacity and incentives of this relatively small network of traders to perform this important market-making role. This leaves derivatives markets acutely vulnerable to the withdrawal of liquidity by dealers. Broadly speaking, there are at least three reasons why dealers might conceivably withdraw from derivatives market-making. First, where a dealer's balance sheet is under pressure, it may withdraw from market-making on the basis that it is not presently able to bear the relevant market, counterparty credit, or other risks. ${ }^{133}$ Insofar as this pressure is isolated to a single dealer, however, we would not expect this to undermine broader market liquidity as other dealers will likely stand ready to step into this dealer's shoes and absorb its market share. Second, during periods of broader market disruption, dealers may take the view that it is not prudent or profitable to enter into new derivatives trades-either because they think they cannot effectively price or manage the relevant risks, or because they wish to insulate their balance sheets from the effects of a possible crisis. Third, dealers may withdraw from derivatives market-making where these activities no longer generate a sufficient return on capital. As examined in Part $\mathrm{V}$, the correlated withdrawal of liquidity by dealers could have a significant impact on the informational efficiency of derivatives markets.

There are perhaps many other reasons why we might view public equity securities and derivatives as fundamentally different species of

131 HARRIS, supra note 113, at 494 (describing specialist obligations).

132 See David Mengle, Int'l Swaps \& Derivatives Ass'n, Concentration of OTC Derivatives Among Major Dealers 2 (2010), http://www2.isda.org/functional-areas/ research/research-notes/page/3. The G14 is comprised of Bank of America, Barclays, BNP Paribas, Citigroup, Credit Suisse, Deutsche Bank, Goldman Sachs, HSBC, JP Morgan Chase, Morgan Stanley, Royal Bank of Scotland, Société Générale, UBS, and Wells Fargo. Id. at 2 n. 2 .

133 Although this may actually exacerbate balance sheet problems insofar as it sends a signal to the market that the dealer's balance sheet is under pressure. 
financial instruments. The pricing models used to value derivatives, for example, are often far more sophisticated than those used to value equity securities. For this and other reasons, many jurisdictions significantly restrict the extent to which the general public can directly participate in derivatives markets-thereby reducing the prospect of both universally informed and uninformed trading. These other differences may have important implications in terms of the relative information and other costs encountered by traders within these markets. Nevertheless, in the next section we confine our examination to four potential mechanisms of market efficiency that have emerged in response to the unique costs stemming from the nature of derivatives contracts, the structure of the markets in which they trade, and the sources of market liquidity.

\section{IV}

\section{The Mechanisms of Derivatives Market Efficiency}

As described in the previous section, traders within derivatives markets face potentially significant information, agency, coordination, and other costs not generally encountered within public equity markets. These costs stem from the need to identify potential counterparties and then screen for and monitor counterparty credit risk over the life of a derivatives contract. They also stem from the economic and legal heterogeneity of derivatives contracts and the opaque dealerintermediated structure of derivatives markets. Against this backdrop, it may at first glance seem remarkable that available empirical evidence suggests that derivatives markets are often relatively informationally efficient. While this evidence is relatively modest in comparison with the voluminous research examining the EMH in relation to public equity markets, it suggests that-at least with respect to certain types of information-some derivatives markets appear to be more sensitive to the revelation of new information than public equity markets. Using news reflected in stock prices as a benchmark for publicly available information, Viral Acharya and Timothy Johnson, for example, find that $C D S$ prices react to negative credit information in a manner consistent with the use of nonpublic information by relationship or "insider" banks. ${ }^{134}$ Lars Norden and Martin Weber similarly find that CDS markets react more rapidly to potential credit rating downgrades than equity markets. ${ }^{135}$ Other studies have found that

134 Viral V. Acharya \& Timothy C. Johnson, Insider Trading in Credit Derivatives, $84 \mathrm{~J}$. Fin. ECON. 110, 112 (2007).

135 Lars Norden \& Martin Weber, Informational Efficiency of Credit Default Swap and Stock Markets: The Impact of Credit Rating Announcements, 28 J. BANkING \& Fin. 2813, 2838 (2004) [hereinafter Norden \& Weber, Informational Efficiency]. But see Lars Norden 
CDS markets lead both bond markets ${ }^{136}$ and credit rating agencies ${ }^{137}$ in reacting to negative news about the creditworthiness of corporate debt issuers. The salient question thus becomes: How exactly does this new information become incorporated into derivatives prices?

This section identifies and examines four potential mechanisms of derivatives market efficiency: dealers, interdealer brokers and ECNs, specialized netting and collateral mechanisms, and contractual standardization under the aegis of organizations such as ISDA. Importantly, these mechanisms are not put forward as substitutes for those identified by Gilson and Kraakman. Indeed, in many cases, these mechanisms may work in tandem with the mechanisms of equity market efficiency. This will particularly be the case where institutional investors-Gilson and Kraakman's professionally informed tradersuse derivatives as a more cost-effective way of creating an exposure to an underlying equity security. ${ }^{138} \mathrm{By}$ the same token, however, the mechanisms of derivatives market efficiency often operate in very different ways from the mechanisms that Gilson and Kraakman argue serve to incorporate new information into prices within public equity markets. These differences reflect the nature of derivatives contracts, the structure of the markets in which they trade, and the sources of market liquidity.

\section{A. Dealers}

As described in Part III, derivatives markets are loosely organized around a relatively small network of global dealers. In order to better understand the central role of dealers within derivatives markets, it may be useful to take a step back and examine the emergence of these markets in historical context. The origins of modern derivatives markets can be traced back to the introduction of the Bretton Woods system of monetary and exchange rate management. ${ }^{139}$ Established in 1944, the Bretton Woods system imposed strict capital con-

\& Martin Weber, The Co-Movement of Credit Default Swap, Bond and Stock Markets: An Empirical Analysis, 15 European Fin. Momt. 529, 530 (2009).

136 Roberto Blanco et al,, An Empirical Analysis of the Dynamic Relation Between Investment-Grade Bonds and Credit Default Swaps, 60 J. FIN. 2255, 2256 (2005).

137 John Hull et al., The Relationship Between Credit Default Swap Spreads, Bond Yields, and Credit Rating Announcements, 28 J. BANking \& Fin. 2789, 2809 (2004).

138 Thus, for example, an institutional investor could use a total return equity swap to create an exposure to an underlying stock. This might be less costly than simply purchasing the underlying shares where (1) the market for the underlying was relatively illiquid or (2) the purchase would send valuable information to other market participants, giving rise to trade decoding, and increasing the price of the stock before the institutional investor was able to acquire the desired amount of stock.

139 For a more detailed history, see Perry Mehrling, The New Lombard Street: How the Fed Became the Dealer of Last Resort 71-75 (2011). 
trols designed to prevent the flight of capital from jurisdictions pursuing relatively tight monetary and macroeconomic policies to jurisdictions pursuing more accommodating policies. ${ }^{140}$ In effect, these capital controls restricted the amount of money that could be moved across international borders.

So-called "parallel loans" - the predecessor of modern swapsemerged as a means of circumventing these controls. ${ }^{141}$ Parallel loans worked as follows. Imagine that Diana's Homemade Apple Pie Stand, domiciled in the UK, required Yen in order to finance the expansion of its burgeoning Japanese subsidiary. Under the Bretton Woods system, Diana's ability to make this investment directly would be severely restricted. However, if Diana could find a Japanese firm that needed Pound Sterling, she could arrange for two parallel loans: one from the Japanese firm to Diana's Japanese subsidiary denominated in Yen, and the other from Diana to the Japanese firm's UK subsidiary denominated in Sterling (see Figure 2) ${ }^{142}$ While these parallel loans would together be economically equivalent to foreign direct investment, no money would cross international borders-thus ensuring that the letter of Bretton Woods, if not its spirit, was strictly observed.

140 The rationale being that, in the absence of such controls, capital would flow to whichever jurisdictions offered the best investment prospects as measured by future growth potential and the cost of capital. While in a floating exchange rate regime we might expect such international capital flows to be reflected in prevailing exchange rates, the Bretton Woods's pegged exchange rate regime prevented currencies from adjusting to fully reflect these flows. For a general discussion of capital controls, see Christopher J. Neely, An Introduction to Capital Controls, Fed. Res. BANK St. LouIs REv., Nov.-Dec. 1999, at 13.

141 Mehrling, supra note 139, at 72-75 (describing how parallel loans were used to circumvent national controls).

142 In reality, the funds for these loans would typically be borrowed by the parent firm from a financial institution located in the relevant jurisdiction. 


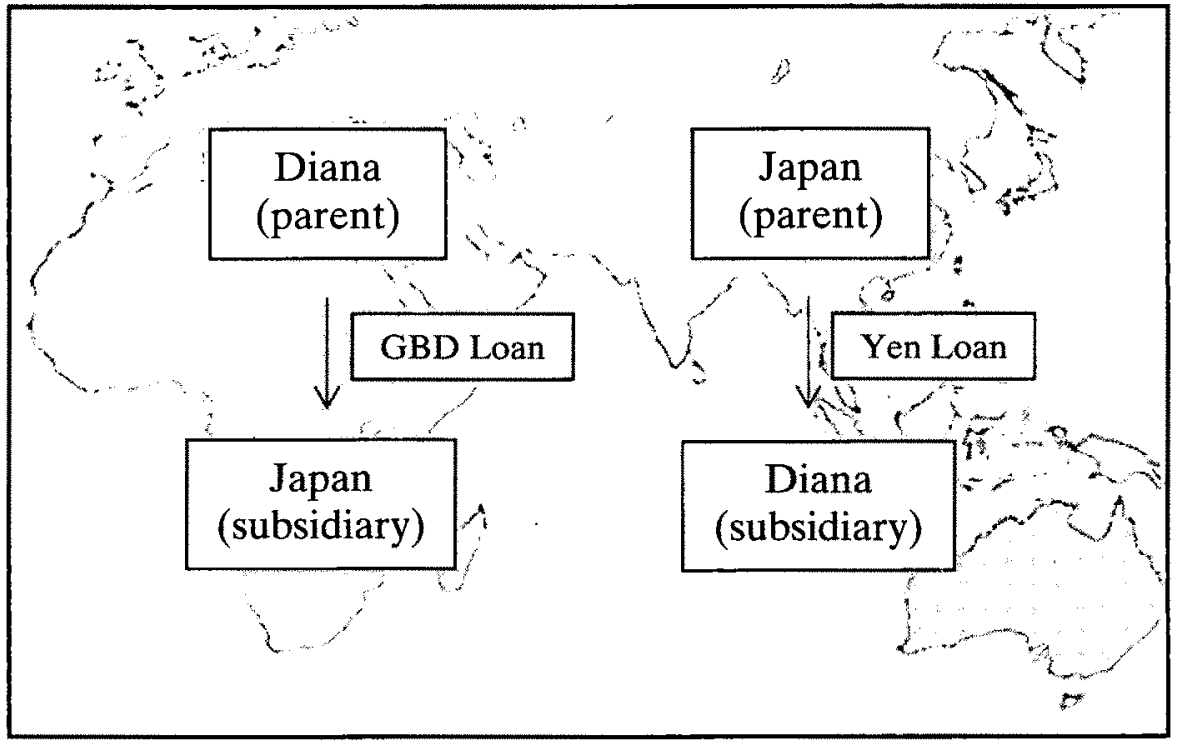

Dealers performed two important functions in the market for parallel loans. First, dealers assist clients like Diana in identifying potential counterparties willing to take the opposite side of a trade. Dealers were in an advantageous position to perform this role for several reasons. As a preliminary matter, dealers were typically large commercial and investment banks whose business it was to understand their clients' business models, financing needs, and creditworthiness. This included understanding the geographic footprint of their. clients' commercial activities and their corresponding demand for financing in foreign currencies. Dealers could then leverage their large client networks in different jurisdictions to match firms whose demand for financing in foreign currency corresponded with one another. Dealers thus played a central role in the aggregation of information about the supply and demand for foreign currency financing in the form of parallel loans, thereby significantly reducing the search costs for firms looking to identify potentially suitable counterparties. As reflected in the composition of the current $\mathrm{G} 14,{ }^{143}$ the resulting economy of scope gave large cross-border banks a comparative advantage in making markets in parallel loans.

Second, dealers played a crucial role in the intermediation of parallel loans. In our example, both Diana's Homemade Apple Pie Stand and the Japanese firm may initially possess very little information about one another. They may also not have the expertise or other

143 See Mengle, supra note 132 , at 2 n.2. 
resources necessary to effectively screen or monitor the creditworthiness of their counterparties. These problems leave both parties extremely vulnerable to counterparty default and opportunism. Perhaps most importantly, in the event that one of the counterparties were to become insolvent, or if it were to opportunistically seek to prematurely terminate one side of the parallel loan, the other counterparty would potentially be left struggling to find a replacement counterparty before it ran out of Yen or Pound Sterling liquidity. The possibility that any new parallel loan entered into under these adverse circumstances might be on less advantageous terms than the original contract is often referred to as "replacement risk."

One way to address these problems is by contractually interposing a dealer that will then lend the UK and Japanese parents the Pound Sterling and Yen necessary for the purpose of extending the loans to each subsidiary (see Figure 3 ). ${ }^{144}$ While the dealer was still exposed to counterparty credit and replacement risk, its balance sheet was also likely to be more diversified and enjoy access to more sources of Pound Sterling and Yen liquidity. This enabled dealers to better absorb counterparty credit, foreign exchange, and other risks, and to bridge any temporal gaps between the financing needs of Diana and the Japanese firm. As sophisticated financial institutions, dealers were also likely to have specialist expertise in screening and monitoring the creditworthiness of their counterparties and to be in a better position to hedge any residual exposures. Perhaps most importantly, the status of dealers as repeat players in the marketplace theoretically imposed reputational constraints that made them less likely to engage in opportunistic behavior. In Gilson and Kraakman's terms, this enabled dealers to function as reputational intermediaries: renting their reputations to their clients as a means of lowering information, agency, and other costs and strengthening the credibility of the commitments underpinning parallel loans. In effect, the reputation of dealers acted as a substitute for investments in information about the creditworthiness of potential counterparties.

144 In practice, the dealers would technically have to extend the loans via their domestic subsidiaries in order to comply with the Bretton Woods capital controls. 


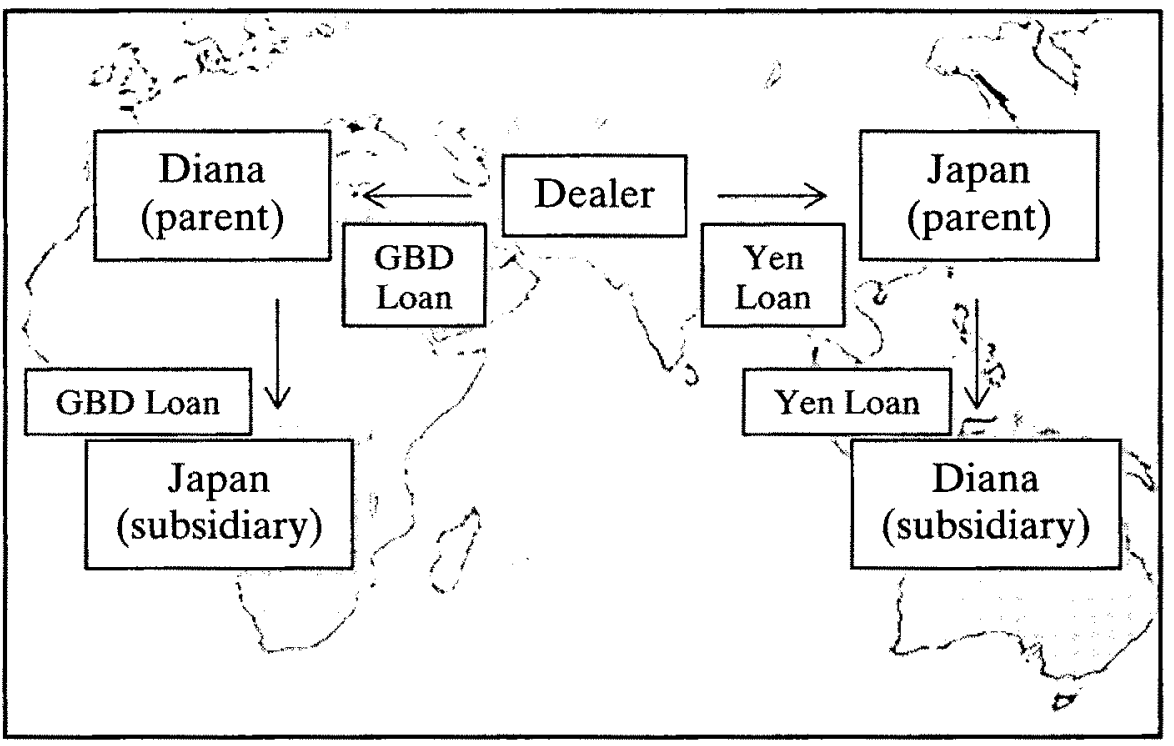

While the Bretton Woods system was incrementally dismantled during the $1970 \mathrm{~s},{ }^{145}$ the financial innovation that it spawned would eventually evolve to become what we now know as foreign exchange or currency swaps. ${ }^{146}$ And like their forebears, modern derivatives markets continue to rely on dealers as the primary source of market information, access, and liquidity. The central position of dealers within the structure of derivatives markets puts them in an advantageous position to acquire and aggregate private information about the creditworthiness of their clients, historical prices, prevailing market conditions, and other trading information. In effect, dealers acquire and aggregate this information as a natural byproduct of their interactions with clients and other dealers as part of the market-making process. Viewed from this perspective, dealers thus represent a new and distinct form of market mechanism: structurally-informed traders.

145 See Peter M. Garber, The Collapse of the Bretton Woods Fixed Exchange Rate System, in A Retrospective on tHE Bretton WoOds System: Lessons for InTERnational. MONeTARY ReForm 461 (Michael D. Bordo \& Barry Eichengreen eds., 1993).

146 Once the Bretton Woods capital controls were removed, parallel loans were no longer required in order to inject capital into foreign subsidiaries. At the same time, the dismantling of the Bretton Woods pegged exchange rate regime meant that many currencies now floated against one another on the basis of market forces. Accordingly, firms needed to manage the foreign exchange risk associated with their foreign operations. By eliminating the requirement to make the actual loan - which had always been costly for dealers because they had to keep it on their books-and focusing instead on exchanging cash flows on the basis of fluctuations in the exchange rate between two currencies, parallel loans thus evolved into the first currency swaps. See Merrurng, supra note 139, at 72-75 (describing how parallel loans were used to circumvent national controls). 
Whereas Gilson and Kraakman's professionally informed traders are incentivized to actively ferret out and trade on new information, structurally informed traders passively acquire this information as a natural byproduct of their market-making activities. ${ }^{147}$

Theoretically, the position of dealers as structurally-informed traders should enable them to extract informational rents from their clients. These rents would likely be embedded in the bid-ask spreads quoted by dealers on different derivatives. The information obtained by dealers as part of their derivatives market-making activities may also be of value to them in other areas-e.g., equity and debt underwriting, fixed income market making, and, where permitted, proprietary trading. ${ }^{148}$ Importantly, this gives dealers powerful incentives to protect the economic value of the information obtained through their privileged market position. In the absence of clear and enforceable intellectual property rights, the most straightforward way to protect the value of this information is to ensure that it is not widely disseminated.

This presents us with something of a puzzle. How does information that is initially distributed to such a narrow group of traders-all of whom possess powerful incentives not to share it-become reflected in derivatives prices? The first part of the answer is that in order to profit from this private information, dealers need to trade on it. As we have seen, traders within derivatives markets will invariably know both the identity of their counterparties and the direction of their exposure to the underlying (at least with respect to that specific trade). Moreover, as described above, a significant volume of derivatives trading takes place between dealers. Thus, for example, JP Morgan will know when it enters into a five-year total return equity swap on Apple shares that its counterparty is Goldman Sachs. It will also likely know that Goldman Sachs was the co-lead underwriter on Apple's $\$ 17$ billion sale of floating rate notes in April 2013,149 and accordingly, that it may possess private information about the firm's creditworthiness and future prospects. The fact that Goldman Sachs takes a long or short position in shares of Apple under the swap thus potentially serves to signal valuable private information to JP

147 At the same time, of course, dealers may also continue to actively seek out and trade on new information, thus simultaneously performing the role of professionally informed traders.

148 See infra section V.A for a very brief discussion of recent restrictions that impact on the ability of some dealers to engage in proprietary trading.

149 Apple Inc., Preliminary Prospectus Supplement (Form 424B2) (Apr. 29, 2013), http:// www.sec.gov/Archives/edgar/data/320193/000119312515028777/d861669d424b2.htm\#toc. 
Morgan. ${ }^{150}$ Such signalling may help explain Acharya and Johnson's findings that the pattern of information revelation within CDS markets is consistent with trading by insider banks on the basis of private information. ${ }^{151}$

It is worth briefly considering what types of private information can be effectively signaled in this way. Intuitively, the strength of the signal will be a function of the recipient's ability to correctly identify which traders are likely to be in possession of private information. It will also be a function of whether the information itself is "hard" financial or strategic information, or "soft" forecasts or other forwardlooking information. Trading by relationship banks, for example, is likely to send a relatively strong signal about the creditworthiness of corporate debt issuers, both because of the certainty surrounding the bank's insider status, and because their assessments are likely to be based on hard financial information. It is thus not surprising that the available empirical evidence suggests that CDS markets rapidly incorporate negative credit information into prices. ${ }^{152}$

However, in many other contexts, it may be far more difficult to determine whether a trader possesses private information. The information a trader possesses may also consist of soft information such as forecasts, and thus be inherently subject to disagreement and divergent interpretations. It seems highly unlikely, for example, that a trader would possess hard private information about future movements in foreign exchange or interest rates. ${ }^{153}$ Moreover, even if the trader did, it is unlikely that other traders would know that the trader was in possession of this information such that they would be able to identify the insider's trades as signalling private information. ${ }^{154}$ Ceteris paribus, it would thus seem far less likely that signalling of this variety would play an important role in the incorporation of new

150 The value of this signal is of course reduced insofar as Goldman Sachs may simply be engaged in market-making for one of its clients.

151 See generally Acharya \& Johnson, supra note 134.

152 See Acharya \& Johnson, supra note 134 and accompanying text; Blanco et al., supra * note 136 and accompanying text; Hull et al., supra note 137 and accompanying text; Norden \& Weber, Information Efficiency, supra note 135 and accompanying text.

153 At least in the absence of market manipulation with respect to the setting of these rates as occurred in the case of the London Interbank Offered Rate (Libor). See HER Majesty's Treasury, The Wheatley Review of Libor: Final Report (2012), https:// www.gov.uk/government/uploads/system/uploads/attachment_data/file/191762/wheatley_ review_libor_finalreport_280912.pdf (detailing market manipulation by several panel banks in connection with the setting of the widely used benchmark interest rate).

154 The notable exception in this regard being central banks, which may be both active participants in interest rate or currency swap markets and possess inside information about impending policy decisions likely to have an impact on the price of the relevant underlying. 
information into prices within these markets. ${ }^{155}$ Accordingly, insofar as existing empirical evidence is largely confined to studies of the CDS market, we must be careful not to overstate claims regarding the informational efficiency of derivatives markets as a whole.

Theoretically, then, trade decoding can help disseminate information within dealer-intermediated derivatives markets. At the same time, the idea that dealers may signal private information through their trading activities raises a host of other important questions. In the absence of an exchange, how can dealers observe the trading activities of other dealers? How can they distinguish between trades designed to offset exposures taken on behalf of clients from those designed to make a directional bet on the basis of private information? And how do they overcome the signalling problems generated by the economic and legal heterogeneity of derivatives contracts? For answers to these questions, we must look to other mechanisms of derivatives market efficiency.

\section{B. Interdealer Brokers and Electronic Trading Platforms}

As described above, dealers play an important role in the intermediation of derivatives markets. As part of this role, dealers often seek to hedge client exposures by entering into offsetting trades. ${ }^{156}$ Where permitted, dealers may also engage in proprietary derivatives trading. ${ }^{157}$ Many of these trades will be entered into with other dealers. Interdealer brokers are intermediaries who enable dealers to exchange information with other dealers regarding their desire to buy or sell derivatives and other financial instruments. The largest interdealer brokers are NEX Group (formerly ICAP), Tullett Prebon, Tradition, BCG Partners, and GFI Group. ${ }^{158}$ As their name suggests, the services of interdealer brokers are generally available only to dealers. Institutional investors and other "buy-side" traders do not typically enjoy access to interdealer brokers' full range of services. ${ }^{159}$

155 Equity derivatives, such as total return swaps, present an interesting case study. On the one hand, it is possible for traders to possess hard private information about the issuer of a public equity security. On the other hand, in the absence of an unambiguous signal analogous to that of the relationship of banks, examined by Johnson and Acharya, it may be difficult for traders to successfully identify whether another trader is acting on the basis of private information.

156 Darrell Duffie, The Failure Mechanics of Dealer Banks, 24 J. Econ. Persp. 51, 56 (2010).

157 Id.

158 Interdealer Brokers: At the Sharp End, Economist (Nov. 17, 2012), http://www .economist.com/news/finance-and-economics/21566651-firms-connect-buyers-and-sellerswholesale-markets-are-under.

159 Although the move of asset managers, such as BlackRock, into derivatives market making is beginning to disrupt this status quo. 
Interdealer brokers will, however, often make some anonymized composite data, such as the average quoted bid-ask spread on various derivatives, available to the broader marketplace. ${ }^{160}$ More granular composite data is available for a fee through market data providers such as Bloomberg and Reuters.

Historically, interdealer brokers have conducted the majority of their business over the telephone. Pursuant to this "voice brokerage" model, individual brokers are responsible for trading a specific instrument and have a direct line with the relevant traders at one or more of the firm's clients. As trade requests are received, these brokers then confer with their colleagues with the objective of identifying another of the firm's clients willing to take the opposite side of the trade. ECNs, meanwhile, enable dealers to communicate with other dealers via dedicated web-based trading portals. Major ECNs include Instinet and NYSE Arca. Once they have identified a potential counterparty, ECNs then enable dealers to execute the trade electronically or engage in further negotiations over the telephone. Some electronic trading platforms also facilitate trading between dealers and their clients. These dealer-to-client platforms enable clients to access quoted bid-ask spreads and other information from either a single dealer or multiple dealers. These quotes will often include different price bands depending upon the client's profile and previous trading history with the specific dealer. Major multiple dealer-to-client platforms include those offered by TradeWeb and Bloomberg.

Interdealer brokers and ECNs play a number of roles in supporting derivatives market efficiency. First, interdealer brokers and ECNs perform a function for dealers broadly analogous to the one that dealers perform for their clients: aggregating information about supply and demand, matching buyers and sellers, and thus lowering search costs within derivatives markets. Second, multiple dealer-toclient ECNs enable clients to compare quotes from different dealers, thereby enhancing competition and ameliorating potential adverse selection and agency problems. Third, by aggregating and disseminating composite market data, interdealer brokers provide dealers and clients with valuable information about prevailing market conditions. Importantly, this composite data can serve as a benchmark

160 The production of this composite data often involves significant interpolation. In many cases, it also does not include information about the size/notional amount of the relevant trades. Marco Avellaneda \& Rama Cont, Int'L Swaps \& Derivatives Ass'n, Transparency in Over-the-Counter InTERest Rate Derivatives Markets 11 (2010), http:/www.isda.org/c_and_a/pdf/IRMarketTransparency.pdf. The informational content of this data is thus open to debate. See Rates Transparency Study, MARKITWIRE (July 2010). 
against which traders can determine whether another trader may be in possession of superior information. Returning to our previous example, if Goldman Sachs is quoting a price that deviates significantly from the reported average for total return swaps on shares of Apple Inc., this may signal to JP Morgan that its counterparty is trading on the basis of private information. ${ }^{161}$ Finally, while interdealer brokers typically offer dealers full pre-trade anonymity, they may nevertheless serve as informal conduits for the transmission of market intelligence regarding, for example, whether a dealer has a large open position in a given derivative or other security. ${ }^{162}$

\section{Netting and Collateral Regimes}

As we have seen, idiosyncratic counterparty credit risk is a potentially significant source of economic and legal heterogeneity within derivatives markets. ${ }^{163}$ This heterogeneity may or may not be reflected in the stated price of a derivatives trade, thereby rendering efficiency-enhancing trade and price decoding more costly. Counterparties use two primary mechanisms to mitigate counterparty credit risk. ${ }^{164}$ The first is closeout netting. Closeout netting involves the termination, valuation, and netting out of contractual obligations in the event of counterparty default or insolvency. ${ }^{165}$ Where the netted closeout amount puts the non-defaulting counterparty in the money, closeout netting entitles this party to immediately seize (as necessary) ${ }^{166}$ and liquidate any collateral posted by the defaulting counterparty in satisfaction of this amount. ${ }^{167}$ Where the defaulting counterparty is in the money, in contrast, closeout netting entitles the non-defaulting party to set off against the amount it owes to the defaulting counterparty any amounts owed to it by the defaulting counterparty. ${ }^{168}$ This set off is available irrespective of whether the

161 Of course, the strength of this signal will be a function of how closely the reported average tracks the actual'price of executed trades.

162 To prevent this, dealers may break up their trades amongst multiple interdealer brokers and counterparties.

163 See discussion supra Part III.A.

164 See John Armour et al., Principles of Financial Regulation (forthcoming 2016) (manuscript at $469-70$ ).

165 Id.

166 In what is ultimately an excellent example of the legal heterogeneity associated with derivatives contracts, the precise operation of closeout netting will depend on whether the relevant collateral was posted pursuant to a title transfer or security interest system. Under a title transfer system, there is technically no need for the non-defaulting counterparty to "seize" the relevant collateral upon default.

167 With any residual amounts owed generally being treated as an unsecured claim in the defaulting counterparty's estate.

168 See JoHN ARMOUR ET AL., supra note 164 (manuscript at 469-70). 
amounts owed to the non-defaulting counterparty are derived from derivatives trades or other obligations. Importantly, the enforceability of closeout netting relies on a series of carve outs-or "safe harbors"-from the automatic stay and fraudulent preference rules under applicable insolvency laws. ${ }^{169}$

The second mechanism used to minimize counterparty credit risk is collateral. Dealers and other counterparties generally seek to minimize their residual net exposures after closeout netting by requiring their counterparties to post collateral - typically cash or highly liquid securities-at the outset of trade. This collateral, often referred to as "initial margin" or the "independent amount," is theoretically designed to reflect each counterparty's exposure to the default of the other counterparty over the duration of the trade. ${ }^{170}$ Thereafter, counterparties may also periodically recalculate the amount of collateral one or both counterparties are required to post. This "variation margin" is designed to reflect changes in the market price of the relevant underlying security. Changes in variation margin may take place in accordance with predetermined contractual triggers-e.g., adverse price movements or a downgrade in a counterparty's credit rating-or be negotiated on a more ad hoc basis in response to market developments. Like closeout netting, the enforceability of these collateral arrangements relies on safe harbors from applicable insolvency laws. ${ }^{171}$

Together, closeout netting and collateral can theoretically transform a trader's exposure to idiosyncratic counterparty credit risk into an exposure to the market risk of the underlying collateral. In order for this transformation to take place, a derivatives trade must meet four conditions. These conditions can be thought of as constituting a first-best state contingent contract. ${ }^{172}$ First, the value of posted collat-

169 For further information about these safe harbors under U.S. insolvency law, see Franklin R. Edwards \& Edward R. Morrison, Derivatives and the Bankruptcy Code: Why the Special Treatment?, 22 Y ALE J. ON REG. 91 (2005) (examining different rationales for the introduction and expansion of the derivatives safe harbors); Frank Partnoy \& David A. Skeel, Jr., The Promise and Perils of Credit Derivatives, 75 U. Cin. L. Rev. 1019 (2007) (examining the impact of credit derivatives on firm governance); Mark J. Roe, The Derivatives Market's Payment Priorities as Financial Crisis Accelerator, 63 STAN. L. Rev. 539 (2011) (examining how the derivatives safe harbors shift risk between a firm's creditors, changing the incentives of creditors to monitor firm-level risk-taking, and potentially contributing to systemic risk). For further information about the equivalent carve outs in the UK and EU, see Alastair Hudson, The Law on Financial DerIVATIVEs 767-94 (5th ed. 2012) (describing the UK equivalent of the derivatives safe harbors).

170 See ARMOur ET AL., supra note 164 (manuscript at 469).

171 Id.

172 In a nutshell, a "first-best" contract can be understood as the one that the parties to a contract would enter into in the absence of cognitive or temporal constraints, imperfect 
eral must in all potential future states of the world at least equal the amount owed to the non-defaulting counterparty after the application of closeout netting. Second, the non-defaulting counterparty must be able to seize this collateral costlessly. Third, the collateral itself must be sufficiently liquid such that the non-defaulting counterparty can rapidly sell it at or near full market value. ${ }^{173}$ This points us in the direction of the optimal forms of collateral: highly liquid and informationally insensitive debt such as cash, U.S. treasury securities, and other highly rated sovereign debt. ${ }^{174}$ The desirability of these forms of financial collateral is reflected in the results of ISDA's 2015 margin survey, in which respondents reported that $76.6 \%$ of collateral received and $77.7 \%$ of collateral delivered in connection with bilaterally cleared derivatives trades was in the form of cash. ${ }^{175}$ Finally, although technically not related to closeout netting and collateral arrangements, the non-defaulting counterparty must secure a credible commitment from a third party to fully insure it against any replacement risk in the event of counterparty default.

Importantly, where these conditions are satisfied, this first-best state contingent contract will put non-defaulting traders in the exact same position they would have been had their counterparty not defaulted. Put differently, this contract renders traders economically indifferent to the creditworthiness of their counterparties, thus eliminating the need for costly counterparty screening and monitoring. Viewed from this perspective, mechanisms such as closeout netting and collateral serve as substitutes for investments in information. Insofar as these mechanisms ensure that counterparties possess symmetric information regarding the consequences of default, they also ameliorate potential adverse selection problems. ${ }^{176}$ Most importantly

information, or other transaction costs. This can be contrasted with a "second-best" contract, which is the best contract the parties are able to write once these costs are taken into account.

173 Or sufficiently over-collateralized that the proceeds of sale, even at a discount, are sufficient to satisfy the first condition.

174 See Gary Gorton \& Guillermo Ordoñez, Collateral Crises, 104 Am. Econ. Rev. 343 (2014) (describing informationally insensitive assets and describing their role in contributing to financial instability); Holmstrom, supra note 108 , at 3 (describing the economic function of collateral as a substitute for information in the context of money markets); Tri Vi Dang et al., Ignorance, Debt and Financial Crises 1 (March 2013) (unpublished manuscript) (discussing how debt, when used as collateral for another debt contract, preserves symmetric ignorance because it minimizes the incentive to produce private information about the payoffs, so debt is least information-sensitive), http:/t www.columbia.edu/ td2332/Paper_Ignorance.pdf.

175 InT'L Swaps \& Derivatives Ass'N, ISDA Margin Survey 2015, at 8 (2015), https://www2.isda.org/functional-areas/research/surveys/margin-surveys/.

176 See Holmstrom, supra note 108, at 5 (describing the economic function of collateral as a substitute for information in the context of money markets). 
for the present purposes, by eliminating the noise generated by the dark side of derivative contracts, these mechanisms can be understood as enhancing the clarity of the signal sent by stated derivatives prices. This, in turn, can be seen as creating a more conducive environment for efficiency enhancing trade and price decoding.

Ultimately, of course, first-best state contingent contracts of the variety described above may be extremely costly. As a preliminary matter, there is little consensus surrounding the methodologies for calculating initial and variation margin requirements for OTC derivatives. At the same time, high quality liquid collateral is increasingly expensive. Counterparties may also incur non-trivial costs in seizing and liquidating it, especially where collateral is located in different jurisdictions and/or subject to different property law or regulatory regimes. Perhaps most importantly, the cost of obtaining credible ex ante insurance against replacement risk from private market participants is likely to be prohibitive given the prospect of highly correlated payouts in the context of widespread market disruption. ${ }^{177}$ As a result, derivatives counterparties may understandably resort to second-best contracts that expose them to some level of risk in the event of counterparty default.

Importantly, where any of these conditions is not satisfied, the economic heterogeneity stemming from idiosyncratic counterparty credit risk and other factors ${ }^{178}$ may continue to generate price distortions that undermine efficiency-enhancing trade and price decoding. At present, there is insufficient publicly available information about closeout netting and collateral practices within global derivatives markets to determine whether or to what extent these conditions are satisfied. ${ }^{179}$ Ultimately, these practices can vary across any number of dimensions: from the amount of pledged collateral, its quality, and whether it can be reused or rehypothecated, to the timing of variation margin calculations, and the circumstances-or triggers-that will require counterparties to post additional margin. As a result, there exists considerable scope for significant levels of economic heterogeneity within derivatives markets. Where this heterogeneity exists, the

177 The role of central banks in this context as "dealers of last resort" is explored in Section V.E.

178 See discussion supra Part III.A.

179 The type of information that would be required in this regard is discussed in Section V.B and Appendix. For an encouraging recent development in this area, see EUROPEAN Cent. Bank, Survey on Credit Terms and Conditions in Euro-denominated Securities Financing and OTC Derivatives Markets (2016), http://www.ecb. europa.eu/press/pr/date/2016/html/SESFOD_report_2016q1.pdf?23a49681fd80aa2bea8f815 $623024 a 72$ (reporting on the European Central Bank's first efforts to study credit terms and conditions in Euro-denominated securities financing and OTC derivatives markets). 
dark side of derivatives markets will cast a shadow over the informational efficiency of derivatives prices.

\section{ISDA and Contractual Standardization}

This leaves legal heterogeneity as a potential obstacle to derivatives market efficiency. It is at this point that we encounter the important role of ISDA in the development of modern derivatives markets. Established in 1985, ISDA is the de facto trade association of the global derivatives industry, representing some 850 member dealers, institutional investors, governments, and other major counterparties. ${ }^{180}$ ISDA's core mandate is to encourage the prudent and efficient development of derivatives markets through the promotion of, inter alia, practices conducive to the efficient conduct of business, sound risk management practices, and high standards of commercial conduct. ${ }^{181}$ While ISDA's contribution toward the development of global derivatives markets can be observed across several dimensions, ${ }^{182}$ two in particular stand out as promoting greater informational efficiency.

First, ISDA has spearheaded the development of specialized legal documentation for use in derivatives trades. Prior to the intervention of ISDA, the majority of derivatives were documented in ad hoc agreements negotiated on a trade-by-trade basis. ${ }^{183}$ The costs of designing, drafting, and negotiating these agreements understandably represented a significant barrier to the growth of derivatives markets. ${ }^{184}$ Stepping into this breach, ISDA commenced publication of its Code of Standard Wording, Assumptions, and Provisions for Swaps in 1985. 185 The ISDA Swaps Code was essentially a glossary of standard terms reflecting then existing practice within the U.S. interest rate swap market. ${ }^{186}$ In 1987 , ISDA published its first standardized "master" agreements for U.S. dollar and multicurrency interest rate swaps and currency swaps. ${ }^{187}$ These master agreements incorporated

180 About ISDA, INT'L Swaps \& DeRIVATrves Ass'N, www2.isda.org/about-ISDA/ (last visited Sept. 2, 2016).

$181 \mathrm{Id}$.

182 For a more comprehensive discussion of the ISDA's contributions to the development of the global derivatives markets, see Awrey, supra note 116, at 200-23.

183 Norman Menachem Feder, Deconstructing Over-the-Counter Derivatives, 17 Colum. Bus. L. REv. 677, 736 (2002) (discussing the development of derivatives markets generally).

184 See id. at 738 (discussing the critical role that standardization of contractual terms played in the development of derivatives markets).

185 Int'l Swaps \& Derivatives Ass'n, Code of Standard Wording, Assumptions and Provisions for Swaps (1985).

186 Feder, supra note 183, at 737.

187 See, e.g., InT'L Swaps \& Derivatives Ass'N, 1987 InTERest Rate and CurRency EXchange Definitions (1987), http://www.isda.org/publications/pdf/1987currdefs.pdf. 
multiple future transactions between two counterparties under the umbrella of a single legal relationship, contemplating only the preparation of a brief confirmation for individual trades. Over time, the scope of these master agreements has been expanded to include equity, commodity, credit, and other derivatives. ${ }^{188}$ ISDA has also developed a series of protocols that facilitate the ex post amendment of existing master agreements with a view towards, inter alia, responding to jurisprudential developments, implementing new advancements, rectifying perceived technical deficiencies, and, more generally, standardizing market practice. ${ }^{189}$ Together, master agreements and protocols serve to reduce the design, drafting, negotiation, and other transaction costs that would otherwise be incurred by counterparties in connection with the preparation of legal documentation for individual trades.

Second, ISDA has taken the lead in promoting international law reform in areas critical to the development of derivatives markets. Perhaps most significantly, ISDA has produced a Model Netting Act and supplemental guidance for legislators in order to assist them in enacting legislation designed to ensure the enforceability of closeout netting and collateral arrangements. ${ }^{190}$ As of July 26, 2011, netting legislation based on this guidance has been adopted in at least 40 jurisdictions, including the United States, EU, Japan, and Canada. ${ }^{191}$ More broadly, ISDA has played an active role in influencing public policy and financial law reform-including the design and implementation of post-crisis reforms targeting derivatives markets, such as Title VII of the Dodd-Frank Act and the European Market Infrastructure Regulation (EMIR). ${ }^{192}$ Whether or not one views the Model Netting Act and other reforms as desirable from a broader social perspective,

188 ISDA has also developed standardized ancillary documentation-including definitions, schedules, credit support agreements, and trade confirmations-for use in connection with these agreements.

189 See Traditional Adherence Protocols, InT'L Swaps \& Derivatives Ass'N, www2. isda.org/functional-areas/legal-and-documentation/protocols/ (last visited July 5, 2016) (listing the protocols available from ISDA).

190 See generally InT'L Swaps \& Derivatives Ass'N, Memorandum on the Implementation of Netring Legislation 1 (2006); 2006 Model Netting Act (Int'L Swaps \& Derivatives Ass'N, 2007).

191 Netting Legislation-Status, INT'L Swaps \& Derivatives Ass'N, http://isda.org/ docproj/stat_of_net_leg.html (last visited Sept. 2, 2016).

192 See generally ISDA Focus: Dodd-Frank, INT'L SwaPs \& Derivatives Ass'N, https:// www2.isda.org/dodd-frank/ (last visited Sept. 2, 2016); ISDA Focus: European Legal and Regulatory Implementation Initiatives, INT'L SwaPS \& DeRIVATIVES Ass'N, http:// www2.isda.org/isda-focus-european-legal-and-regulatory-implementation-initiatives/ (last visited Sept. 2, 2016). 
there is little doubt that they have contributed to the spectacular growth of derivatives markets in recent decades. ${ }^{193}$

Based on the two contributions described above, the benefits of ISDA's activities can be understood as flowing largely from contractual standardization: both in terms of the contracts themselves and the statutory frameworks that ensure their effective enforcement. Master agreements standardize legal terms and terminology; protocols ensure consistency between past and future contracts; and netting legislation ensures equivalent treatment of closeout netting and financial collateral arrangements across jurisdictions. This standardization makes derivatives easier to write and understand. The standardization of legal terms also makes it easier for counterparties-and dealers in particular - to effectively hedge their derivatives exposures.

In order to understand why contractual standardization is so important, imagine a dealer standing between two clients on opposite sides of a trade (see Figure 4). Imagine also that the dealer and each client were domiciled in, and subject to the laws of, different jurisdictions. The dealer, as we have already seen, would theoretically prefer to maintain a matched book and simply charge a fee for intermediating the trade and assuming the resulting counterparty credit and other risks (which, of course, it may then also seek to shift by entering into offsetting trades). However, complications would arise if the courts in one jurisdiction (Jurisdiction A) issued an interpretation of a material term of ISDA's master agreement that was inconsistent with its interpretation in another jurisdiction (Jurisdiction C). Alternatively, what if applicable insolvency laws in Jurisdiction A contained safe harbors from the automatic stay and fraudulent preference provisions - thereby enabling counterparties to closeout their positions and seize collateral upon another counterparty's default-but Jurisdiction C's insolvency legislation did not?

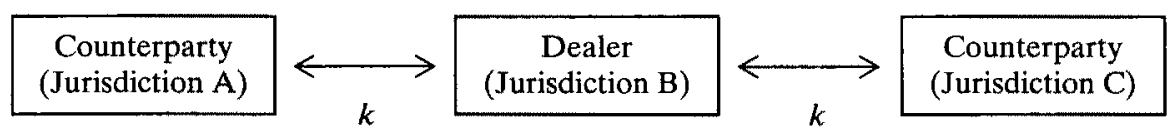

Dealers can largely resolve the first problem by ensuring that the contracts are both governed by the laws of a single jurisdiction, in

193 For a discussion of the potential moral hazard and other problems stemming from the safe harbors for derivatives under U.S. bankruptcy law, see Edwards \& Morrison, supra note 169, at 121; Partnoy \& Skeel, supra note 169, at 1033; Roe, supra note 169, at 555 . 
practice, typically either the U.S. or UK. ${ }^{194}$ The second problem, however, is potentially more difficult to resolve. At the very least, this legal heterogeneity would make it more complex-and thus more costly - for dealers to manage the resulting economic differences between the two sides of the trade (commonly known as "basis" risk). In extremis, this basis risk might even undercut the incentives of dealers to enter into derivatives with counterparties subject to the insolvency laws of Jurisdiction $C$, thereby undercutting the economies of scope associated with dealer intermediation.

With these potential problems in mind, contractual standardization promoted by organizations such as ISDA can be understood as making two important contributions to market efficiency. First, contractual standardization reduces legal and economic heterogeneity, thereby ameliorating a potentially significant source of efficiencyinhibiting price distortions. Second, standardization reduces the information, negotiation, hedging, and other costs of financial intermediation. Insofar as the reduction of these costs makes it more attractive for dealers to make markets in derivatives, this standardization can thus be seen as contributing to market liquidity-thereby improving the process of price discovery, and promoting greater informational efficiency within derivatives markets. ${ }^{195}$

The objective of this section has not been to suggest that derivatives markets are relatively informationally efficient. This is ultimately an empirical question that resides beyond the scope of this paper. Moreover, it seems intuitively likely that different derivatives markets will incorporate new information into prices at different speeds and in different ways. What this section has instead attempted to do is examine some of the existing institutional arrangements that might serve to promote greater informational efficiency within derivatives markets and, importantly, how they theoretically respond to the information and other problems stemming from the nature of derivatives contracts, the structure of the markets in which they trade, and the sources of market liquidity. In the process, this section has also examined some of the costs associated with these arrangements, and thus their practical limits as mechanisms of derivatives market effi-

194 As of April 2010, it is estimated that these two jurisdictions accounted for approximately $70 \%$ of global turnover in interest rate derivatives, and $55 \%$ of the global turnover in foreign exchange derivatives. BANK FOR INT'L SetTlements, TrIENNIAL Central Bank Survey: Foreign Exchange and Derivatives Market Activity in APRIL 2010, at 5-6 (2010). Unfortunately, the triennial survey in 2013 did not provide an update of these estimates.

195 These non-dealer counterparties may also benefit from a reduction in legal and other forms of basis risk insofar as they, too, are entering into multiple (potentially offsetting) swaps with multiple counterparties. 
ciency. The next section examines some of the important policy implications that flow from this analysis.

\section{$\mathrm{V}$ \\ Policy Implications}

This examination of the mechanisms of derivatives markets efficiency raises a host of important and timely policy questions. ${ }^{196}$ The most important of these questions revolve around the potential impact of recent regulatory reforms introduced in the wake of the 2008 financial crisis. These reforms include the introduction of new derivatives trade reporting and disclosure requirements, a greater emphasis on macroprudential surveillance of derivatives markets, the shift toward mandatory central clearing for many standardized derivatives, and the imposition of new and more onerous prudential requirements on derivatives dealers under Basel III. 197 This examination also raises important questions about the optimal balance between public and private ordering within derivatives markets. This section examines each of these policy questions in greater detail.

\section{A. Derivatives Trade Reporting and Disclosure}

Promoting greater market efficiency is frequently identified as one of the fundamental objectives of securities regulation. ${ }^{198}$ In pursuit of this objective, securities laws typically impose pre-trade transparency requirements on stock exchanges and other trading platforms to publicly disseminate prevailing bid, ask, volume, and other market information. ${ }^{199}$ They also require post-trade dissemination of price,

196 Yesha Yadav has already examined one of these policy questions: namely, whether we need to rethink our approach toward the regulation of insider trading within derivatives-and in particular CDS-markets. See Yesha Yadav, Insider Trading in Derivatives Markets, 103 GEO. L.J. 381 (2015).

197 See infra Part $\mathrm{V}$ for a more detailed exploration of these policy questions.

198 See John C. Coffee, Jr., Market Failure and the Economic Case for a Mandatory Disclosure System, 70 VA. L. REV. 717 (1984) (examining the case for mandatory disclosure regimes as a mechanism for promoting market efficiency); Zohar Goshen \& Gideon Parchomovsky, The Essential Role of Securities Regulation, 55 DUKE L.J. 711 (2006) (arguing that the essential role of securities regulation is to create a market for professionally informed traders).

199 See Securities Exchange Act of 1934, Pub. L. 73-291, 48 Stat. 881 (codified as amended at 15 U.S.C. \$ 78a-78pp (2012)); Regulation NMS, 70 Fed. Reg. 37,496 (June 29, 2005) (codified at 17 C.F.R. pts. 200, 201, 230, 240, 242, 249 \& 270) (establishing new rules for the dissemination of market information). Alternative trading platforms are a notable exception, where regulatory rules contemplate the non-application or waiver of pre-trade transparency requirements in certain circumstances. See, e.g., Regulation of Alternative Trading Systems, 64 Fed. Reg. 19,450 (Apr. 21, 1999) (codified at 17 C.F.R. pts. 202, 240, $242 \& 249)$. 
volume, and other information in connection with executed trades. ${ }^{200}$ Historically, derivatives have been largely exempt from the application of these pre- and post-trade transparency requirements. ${ }^{201}$ In response to the recent financial crisis, however, policymakers in the U.S. and elsewhere have introduced a number of regulatory reforms designed to enhance the transparency of derivatives markets.

Section 727 of the Dodd-Frank Act, for example, mandates posttrade reporting of price, volume, and other information for all swaps to a registered swaps data repository (SDR). ${ }^{202}$ The information that must be reported to an SDR under section 727 includes the notional value of the swap; the stated price or exchange rate; whether any counterparty to the swap is a dealer, major swap participant (MSP), or financial entity; whether the swap is collateralized; the date and time it was executed; and its maturity, termination, or end date. ${ }^{203}$ This information must be reported by a designated counterparty at the time the swap is executed. ${ }^{204}$ The designated counterparty must also report any changes to the primary economic terms of the swap over the life of the contract. 205

Section 727 of the Dodd-Frank Act also imposes an affirmative obligation on SDRs to ensure the real-time public dissemination of certain anonymized information in relation to executed trades. ${ }^{206}$ This obligation applies to all swaps subject to SDR reporting requirements (other than certain foreign exchange derivatives) ${ }^{207}$ that are executed as part of an "arm's-length transaction between two parties that

200 Securities Exchange Act of 1934, supra note 199; see also Regulation NMS, supra note 199.

201 See William C. Meehan \& Gabriel D. Rosenberg, OTC Derivatives Regulation Under Dodd-Frank: A Guide to Registration, Reporting, Business CONDUCT, AND ClEARING 70-71 (2014) (describing the pre-Dodd-Frank Act regulation of OTC derivatives markets).

202 Dodd-Frank Wall Street Reform and Consumer Protection Act, Pub. L. No. 111-203, $\S 727,124$ Stat. 1376, 1696 (2010). The basic requirement articulated in section 727 is then supplemented by regulatory rules prescribing in greater detail what information is to be reported. Swap Data Recordkeeping and Reporting Requirements, 17 C.F.R. pt. 45 (2012) [hereinafter SDR Reporting Rule].

203 SDR Reporting Rule, supra note 202, app. 1.

204 SDR Reporting Rule $\& 45.8$ provides a hierarchy for the purposes of determining which counterparty is required to report the relevant information. SDR Reporting Rule, supra note 202, \& 45.8; see also MEEHAN \& ROSENBERG, supra note 201, at 72-75.

205 MeEHAN \& Rosenberg, supra note 201, at 75-76.

206 Once again, this basic requirement is then supplemented by more detailed rules prescribing what information SDRs are required to disseminate. Real-Time Public Reporting of Swap Transaction Data, 17 C.F.R. pt. 43 (2012) [hereinafter Real-Time Reporting Rule].

207 And specifically those subject to the Treasury Amendment. Determination of Foreign Exchange Swaps and Foreign Exchange Forwards Under the Commodity Exchange Act, 77 Fed. Reg. 69,694 (Nov. 20, 2012). 
results in a corresponding change in the market risk position between the two parties." 208 This obligation is coupled with a negative obligation not to disseminate information "in a manner that discloses or otherwise facilitates the identification of a party to a swap." 209 There is also an exception for information relating to block trades and other large transactions, the dissemination of which may be subject to a brief delay. ${ }^{210}$ The information that must be publicly disseminated by SDRs includes the notional value of the swap; the stated price or exchange rate; the underlying assets; whether the swap is bilaterally or centrally cleared; and whether it is collateralized, along with its settlement currency, payment and reset frequency, and effective start and end dates. ${ }^{211}$ In order to ensure the uniform distribution of this information within the marketplace, dealers and MSPs are prohibited from disclosing swap transaction and pricing data prior to its dissemination by the relevant SDR. ${ }^{212}$ Simultaneously, however, dealers and MSPs are permitted to disclose this information to their clients at the same time as they report it to the SDR, provided that the counterparties to these trades are notified in advance and that the disclosure is nondiscriminatory. ${ }^{213}$ Where this disclosure takes place, these clients will thus receive potentially valuable information before it is available to the wider marketplace.

In addition to this extensive post-trade reporting and disclosure, the Dodd-Frank Act also introduces a limited degree of pre-trade transparency. Section 723 requires that derivatives subject to mandatory central clearing 214 be executed on either a "designated contract market" (DCM) or "swap execution facility" (SEF)..$^{215}$ DCMs are essentially options and futures exchanges that, technically at least, also facilitate trading in swaps. ${ }^{216} \mathrm{DCMs}$ thus typically route submitted bids and asks into a transparent central order book and

\footnotetext{
208 Real-Time Reporting Rule, supra note 206, $\S 43.2$.

209 Id. \& 43.4(d)(1).

210 See Meenan \& Rosenberg, supra note 201, at 102-04 (describing the types of trades that are subject to delays and the prescribed length of the delay).

211 Real-Time Reporting Rule, supra note 206, app. A.

212 Id. \$ 43.3(b)(3)(ii).

213 Id. $\$ 43.3$ (b)(3)(ii)(A)-(D).

214 See infra Section V.C (discussing the evolution of derivatives regulation with the introduction of mandatory central clearing).

215 Unless the swap is not available to trade. In order to be available to trade, a swap must either be listed for trading on a DCM or SEF or have been submitted to the CFTC for review as potentially subject to the mandatory clearing requirement. Process for a Designated Contract Market or Swap Execution Facility to Make a Swap Available to Trade, Swap Transaction Compliance and Implementation Schedule, and Trade Execution Requirement Under the Commodity Exchange Act, 78 Fed. Reg. 33,606 (June 4, 2013) (codified at 17 C.F.R. $\$ \$ 37.10,38.12$ ).

216 In practice, DCMs have rarely been used to facilitate trading in swaps.
} 
then, much like conventional stock exchanges, use order-matching and trade-pricing rules to match buyers and sellers. SEFs, in contrast, are trading platforms designed solely to facilitate trading in swaps. In addition to routing trades through a central order book, SEFs may also operate on the basis of a "request-for-quote" (RFQ) system. The Commodity Futures Trading Commission describes a RFQ system as "a trading system or platform in which a market participant transmits a request for a quote to buy or sell a specific instrument to no less than three market participants in the trading system or platform, to which all such market participants may respond."217 An SEF that offers an RFQ system for any swap subject to mandatory central clearing is required to inform a trader requesting a quote of any firm bids or asks currently in its order book for the same contract. ${ }^{218}$ SEFs are also prohibited from using any mechanism that prevents a trader from viewing the bids or asks communicated by other traders, or that impedes the ability of a trader to interact or trade with any other trader. ${ }^{219}$

The stated objective of the Dodd-Frank Act derivatives reporting and disclosure requirements is to make swap transaction and pricing data available to the public on a timely basis in order to enhance the process of price discovery. ${ }^{220}$ The trade execution requirements for swaps subject to mandatory central clearing are similarly designed to enhance price discovery and improve pre- and post-trade price transparency. ${ }^{221}$ On first inspection, it seems likely that these requirements are likely to provide many derivatives traders with more information about prevailing market conditions, along with price and other transaction data in connection with executed trades. ${ }^{222}$ Amongst other benefits, these requirements may serve to reduce search costs for traders seeking multiple competitive quotes, thereby reducing the potentially acute adverse selection and agency problems embedded within the dealer-intermediated structure of derivatives markets.

217 Core Principles and Other Requirements for Swap Execution Facilities, 78 Fed. Reg. 33,476 (June 4, 2013) (codified at 17 C.F.R. pt. 37).

218 Id.

219 Div. of Clearing \& Risk, Div. of Mkt. Oversight, and Div. of Swap Dealer and Intermediary Oversight, U.S. Commodity Futures Trading Comm'n, guidance on application of Certain Commission Regulations to Swap Execution Facilities 1-3 (2013).

220 Dodd-Frank Wall Street Reform and Consumer Protection Act, Pub. L. No. 111-203, $\S 727,124$ Stat. 1376, 1696 (2010).

221 S. REP. No. 111-176, at 33-34 (2010).

222 Although, given the historic opacity of derivatives markets, it is admittedly difficult to establish a benchmark against which to make this comparison. 
However, while the new derivatives trade reporting and disclosure requirements will likely provide the marketplace and regulators with more information, whether they will serve to promote greater market efficiency is ultimately a different question. As a preliminary matter, these requirements do little to shine a light on the economic and legal heterogeneity that may reside just beneath the surface of the information that market participants are required to report, and which SDRs are required to publicly disseminate. Take collateral for example. When disseminating trading information, SDRs are merely required to provide an indication of whether a swap is collateralized. ${ }^{223}$ The binary nature of this requirement disregards the fact that-as we have already seen-derivatives collateral arrangements can vary across a number of important dimensions, for example the amount of pledged collateral, its quality, restrictions on reuse and rehypothecation, and the timing and triggers of any variation margin requirements. Each of these dimensions is relevant to the question of how large each trader's exposure is to the idiosyncratic credit risk of its counterparty. These requirements will thus not provide traders with sufficiently granular information to isolate the impact of economic and legal heterogeneity on the stated price of a derivatives contract, thereby failing to remove a potentially significant barrier to effective price discovery and informational efficiency.

Another potential barrier to greater market efficiency stems from the fact that both the pre- and post-trade transparency requirements introduced under the Dodd-Frank Act envision that disseminated transaction data will be almost completely anonymized. This anonymity can be understood as inhibiting market efficiency in at least two ways. First, not knowing the identity of the counterparties to a derivatives trade-for example whether a swap involves Apple Inc. or Diana's Homemade Apple Pie Stand-makes it impossible for other traders to isolate and measure the potential price distortions generated by idiosyncratic counterparty credit risk. Second, and along the same vein, anonymity undermines the ability of traders to engage in efficiency-enhancing trade decoding. While some degree of trade decoding may still be possible as a result of the preferential treatment afforded to the clients of dealers and MSPs, ${ }^{224}$ it thus seems somewhat unlikely that the anonymization of trading information under these new transparency requirements will create a conducive environment for derivatively informed trading.

223 Real-Time Reporting Rule, supra note 206, app. A.

224 Which will not only have advance access to trading information but, crucially, will also know the identity of at least one of the counterparties. 
Perhaps counter-intuitively, the optimal policy response to the lack of publicly available information about the identity of counterparties and the precise terms of their contractual arrangements-in short, the dark side of derivatives markets-may not be to shine additional light on it. Indeed, as Kate Judge has observed, mandating further transparency in this context would actually serve to increase information costs for traders, 225 thereby undermining the prospective benefits of mechanisms such as closeout netting and collateral designed to serve as substitutes for investments in information about the creditworthiness of derivatives counterparties. Once this veil of mutual ignorance has been lifted, we might expect some counterparties-namely dealers-to be in a better position to evaluate this new information. Recognizing this advantage, other traders may be reluctant to enter into trades with these counterparties. Viewed from this perspective, greater transparency may actually give rise to an adverse selection problem, thereby undercutting market liquidity and reducing the informational efficiency of derivatives markets.

Finally, one might question whether the Dodd-Frank Act trade reporting and disclosure requirements could potentially serve to undercut the economic incentives of dealers to make markets in derivatives. In examining this question, it may be useful to compare derivatives markets with the dealer-intermediated markets for corporate, government, and other bonds. Here, available empirical evidence generally suggests that the introduction of post-trade transparency requirements is unlikely to have a significant impact on market liquidity. For example, a 2007 empirical study conducted by Michael Goldstein, Edith Hotchkiss, and Eric Sirri found that the introduction of post-trade transparency requirements in connection with certain U.S. corporate bond markets was correlated with narrower bid-ask spreads and, crucially, did not result in lower trade volumes. ${ }^{226}$ Simultaneously, however, Hendrick Bessembinder and William Maxwell have found that dealers held lower inventories of bonds and engaged in less proprietary trading after the introduction of these requirements, ${ }^{227}$ suggesting that greater pre-trade transparency had diluted some of the ancillary economic benefits of making markets.

Intuitively, we would expect the introduction of pre-trade transparency requirements to have a more significant impact on derivatives

225 Judge, supra note 14 , at $31-37$.

226 Michael A. Goldstein et al., Transparency and Liquidity: A Controlled Experiment on Corporate Bonds, 20 REv. FIn. STUd. 235, 237 (2007).

227 Hendrik Bessembinder \& William Maxwell, Markets: Transparency and the Corporate Bond Market, 22 J. ECON. PersP. 217, 228, 231 (2008). 
market liquidity. This intuition stems from the fact that pre-trade transparency requires dealers to disclose their quotes to the marketplace, thereby enabling other market participants to more easily compare prices (thereby promoting greater competition) and potentially signaling private information to the market (thereby reducing the opportunity for dealers to profit from it). These requirements can thus be understood as reducing the expected payoffs for dealers acting in their capacity as structurally informed traders, and potentially incentivizing them to cut back on their market-making activities. They can similarly be understood as undercutting the incentives of professionally informed traders to acquire, analyze, verify, and trade on new information. Indeed, it seems highly likely that the anonymity requirements and block trade delays under the Dodd-Frank Act trade reporting and disclosure rules have been introduced precisely to protect the economic incentives of dealers and professionally informed traders. Paradoxically, then, greater transparency may result in reduced liquidity, impede the process of price discovery, and contribute to greater informational inefficiency within derivatives markets.

\section{B. Macroprudential Surveillance of Derivatives Markets}

A second objective of the Dodd-Frank Act reporting and disclosure requirements is to enhance the macroprudential surveillance of derivatives markets by the newly created Financial Stability Oversight Council and other members of the U.S. supervisory and regulatory community. ${ }^{228}$ One of the most important lessons of the financial crisis was that the effective microprudential regulation and supervision of banks and other financial institutions must be combined with a rigorous and comprehensive assessment of potential macroprudential risks. ${ }^{229}$ While the precise definition of macroprudential risk is still

228 See MeEhan \& Rosenberg, supra note 201, at 71-72 (discussing how the SDR reporting framework increases the regulatory burden for swap market participants).

229 See, e.g., Claudio Borio, Towards a Macroprudential Framework for Financial Supervision and Regulation?, 49 CESIFO ECON. STud. 181 (2003) (defining microprudential and macroprudential regulation and arguing for a shift of emphasis toward the latter); Samuel G. Hanson et al., A Macroprudential Approach to Financial Regulation, 25 J. ECON. PersP. 3 (2011) (articulating a detailed vision for how macroprudential regulation and supervision might be designed); Robert Hockett, The Macroprudential Turn: From Institutional 'Safety and Soundness' to 'Systemic Financial Stability' in Financial Supervision, 9 VA. L. \& Bus. Rev. 201 (2015) (examining the legal challenges to the effective implementation of macroprudential regulatory regimes); Andrew Crockett, Gen. Manager, Bank for Int'l Settlements, Remarks Before the Eleventh International Conference of Banking Supervisors (Sept. 18, 2000), http://www. bis.org/review/r000922b.pdf (discussing the relationship between microprudential and macroprudential stability). 
somewhat contested, it can be understood as encompassing at least two different types of risks. ${ }^{230}$ The first are cross-sectional risks generated by various direct and indirect transmission mechanisms that create complex and often hard to detect interconnections among and between different financial markets and institutions. The second are time series risks generated by the procyclicality of the financial cycle, or arising by virtue of the interactions between financial and business cycles. 231

Derivatives pose a number of potentially significant macroprudential risks. Perhaps most obviously, derivatives can generate cross-sectional risks as a result of direct counterparty exposures: the financial distress or insolvency of one firm, operating within a particular jurisdiction or segment of the financial services industry, has the potential to undermine the stability of its derivatives counterparties in other jurisdictions or market segments. ${ }^{232}$ The risks stemming from this type of "domino" effect are arguably magnified by the dealer-intermediated hub-and-spoke counterparty network at the heart of derivatives markets. The collective actions of derivatives traders can also generate indirect cross-sectional risks, such as those arising from the correlated withdrawal of liquidity by dealers during periods of market turmoil. Once again, given the highly concentrated dealer-intermediated structure of derivatives markets and the widespread use of derivatives across a broad range of (nonfinancial) sectors, such correlated withdrawals can have reverberations far outside the financial system.

Derivatives can also contribute to the procyclicality of the financial cycle. In order to understand how, we need to first understand how derivatives can generate high levels of (implicit) leverage. 233 Imagine that Diana, our market-savvy baker, enters into a total return equity swap on shares of Apple Inc. with a notional value of US $\$ 10$ million and semiannual payments of five percent. In effect, Diana has contracted to pay her dealer US\$500,000 every six months, in exchange for which she will receive payments from the dealer equal to any capital appreciation and dividends on US $\$ 10$ million worth of Apple shares. If the price of Apple Inc. declines, meanwhile, Diana

230 See ARMOUR ET AL., supra note 164 (manuscript at 410).

231 See Claudio Borio, The Financial Cycle and Macroeconomics: What Have We Learnt?, 45 J. BANKING \& Fin. 182 (2014) (examining the role of the financial cycle in macroeconomics and macroprudential policy).

232 ARMOUR ET AL., supra note 164 (manuscript at 470-72).

233 See generally Jonathan R. Macey, Derivative Instruments: Lessons for the Regulatory State, 21 J. CoRp. L. 69, 82 (1995); Frank Partnoy, Financial Derivatives and the Costs of Regulatory Arbitrage, 22 J. CORP. L. 211, 225-26 (1997). 
will be required to pay the dealer an amount equal to the value of this decline. From a basic economic perspective, this swap is identical to Diana simply borrowing US $\$ 10$ million from the dealer on margin at a rate of five percent interest and then investing the proceeds in Apple shares. And like all debt financing, the implicit leverage associated with derivatives means that relatively small changes in the market price of the underlying can have a significant impact on the liquidity and solvency of debtor counterparties.

That derivatives are essentially a form of debt instrument should come as no surprise: What is idiosyncratic counterparty credit risk, after all, if not the exposure of a lender to the default of a borrower? Viewed in this light, many of the contractual terms underpinning a derivatives trade become important determinants of the nature and extent of this implicit leverage. Thus, for example, the quality and amount of collateral that Diana (or the dealer) is required to post will, in effect, determine the extent to which Diana's obligations to the dealer (and vice versa) should be viewed as constituting secured debt. Similarly, the precise conditions under which Diana will be required to post additional collateral during the life of the contract will have important implications in terms of the allocation of risk between debtor and creditor counterparties. Where these collateral requirements, variation margin triggers, and other contractual terms are relatively debtor friendly, this can ultimately be viewed as contributing to the build-up of potentially socially suboptimal levels of indebtedness within the financial system.

Against this backdrop, it is highly doubtful that the Dodd-Frank Act derivatives reporting and disclosure requirements compel dealers and other counterparties to report the type or granularity of information needed to support effective macroprudential surveillance. ${ }^{234}$ As described above, the trade-level data required to be reported to an SDR pursuant to section 727 includes: the notional value of a swap, its price, whether one or both of the counterparties is a dealer, MSP, or financial entity, and whether the swap is collateralized. ${ }^{235}$ Notably, however, these requirements do not require ongoing reporting of gross market values or other measures of a counterparty's net exposure over the life of a swap. Nor-beyond the mere fact of whether a swap is or is not collateralized-do these requirements mandate reporting of economically important terms such as the amount of

234 Although, once again, recent exercises such as the ECB's survey of credit conditions in securities lending and derivatives markets are a step in the right direction. See EUROPEAN CENT. BANK, supra note 179 (collecting information on trends in the credit terms offered by firms in derivatives markets).

235 SDR Reporting Rule, supra note 202, app. 1. 
posted collateral, its composition and quality, or whether it can be reused or rehypothecated in connection with other transactions. Perhaps most importantly, these requirements do not compel detailed reporting of the triggers pursuant to which counterparties may be required to post additional variation margin. As a result, supervisors may find themselves with insufficient data for the purposes of measuring the level of leverage within derivatives markets, or identifying circumstances where contractual terms may facilitate correlated runlike behavior by derivatives and other counterparties as occurred in advance of the failure of Bear Stearns, Lehman Brothers, and AIG. ${ }^{236}$ To return to our earlier analogy, macroprudential supervisors may thus struggle to see anything beyond the tip of the derivatives iceberg. Appendix A identifies several contractual data points that regulators could theoretically collect through SDRs for the purpose of enhancing their macroprudential surveillance of derivatives markets.

\section{Mandatory Central Clearing of Standardized Derivatives}

The Dodd-Frank Act trade reporting and disclosure requirements represent an important step in the evolution of derivatives regulation. Arguably more important, however, has been the introduction of mandatory central clearing for many standardized swaps. Section 723 of the Dodd-Frank Act makes it unlawful for a trader to enter into any swap that meets certain standardization, liquidity, and other requirements unless that swap has been accepted for clearing by an authorized clearinghouse. ${ }^{237}$ The perceived benefits of central clearing flow principally from the mechanisms that clearinghouses employ to

236 See Cong. Oversight Panel, The AIG Rescue, Its Impact on Markets, and the Government's Exit Strategy, S. Doc. No. 56-698, at 29-36, 55-58 (2010) (examining the reasons for the failure of AIG and the mechanics of the subsequent bailout); Duffie, supra note 156 (describing the vulnerability of dealers to runs by derivatives and repo counterparties and other creditors); Roe, supra note 169, at 550-54 (describing the runs by derivatives and repo counterparties on AIG, Bear Stearns, and Lehman Brothers).

237 The mandatory clearing requirement under section 723 does not apply to commercial end-users entering into swaps for the purpose of hedging or mitigating commercial risk. When determining whether a swap should be subject to mandatory clearing, the CFTC must take into account the aggregate outstanding notional value of the relevant species of swap, the level of market liquidity, the availability of pricing data, the robustness of the infrastructure needed to clear the swap, the effect of central clearing on systemic risk and competition, and the existence of reasonable legal certainty with regards to the treatment of counterparty positions, funds, and property. Dodd-Frank Wall Street Reform and Consumer Protection Act, Pub. L. No. 111-203, \& 723, 124 Stat. 1376, 1675 (2010) (codified at 7 U.S.C. $\& 2(\mathrm{~h})(2)(D)$ ). The SEC has adopted similar rules for swaps falling under its jurisdiction. Process for Submissions for Review of Security-Based Swaps for Mandatory Clearing and Notice Filing Requirements for Clearing Agencies, 77 Fed. Reg. 41,602 (July 13, 2012) (codified at 17 C.F.R. $\$ 240 . C 3 a-1,249$ ). 
manage counterparty credit risk. ${ }^{238}$ First, clearinghouses utilize multilateral netting as a means of eliminating offsetting exposures, thereby reducing the overall size and number of payment obligations and thus each counterparty's exposure in the event of counterparty default. ${ }^{239}$ Second, clearinghouses seek to minimize residual net exposures after multilateral netting by requiring counterparties to post both initial and variation margin. ${ }^{240}$ Unlike many bilaterally cleared swaps, however, the variation margin demanded by clearinghouses is calculated on a daily (or even more frequent) basis in order to reflect market movements in the price of the underlying security. ${ }^{241}$ Third, clearinghouses employ a number of other loss sharing mechanisms designed to minimize the risk of market disruption in the event of the failure of one or more of its dealer (or "clearing") members. ${ }^{242}$ These mechanisms include pre-committed default funds, recourse to the clearinghouse's own capital, clearing member capital calls, and so-called "position portability" procedures. ${ }^{243}$ Collectively, these mechanisms-often referred to as a clearinghouse's "default waterfall"-can be understood as mutualizing the risks stemming from the default of one or more clearing members.

A great deal of scholarship has already been written examining the economics of central clearing, ${ }^{244}$ the governance and risk management of clearinghouses, ${ }^{245}$ the potential for regulatory arbitrage, ${ }^{246}$

238 ARMOUR ET AL, supra note 164 (manuscript at 472-74). For a more detailed description of the mechanisms clearinghouses use to address counterparty credit risk, see Craig Pirrong, The Economics of Clearing in Derivatives Markets: Netting, Asymmetric Information, and the Sharing of Default Risks Through a Central Counterparty (Jan. 8, 2009) (unpublished manuscript), http://papers.ssrn.com/sol3/papers.cfm?abstract_id=1340 660 (analyzing the implications of the adoption of central clearing in relation to alternative mechanisms for sharing default risks).

239 Clearinghouses also use "trade compression." Trade compression is a process whereby economically redundant contracts are eliminated, thereby reducing the number of contracts outstanding between two counterparties without impacting their net positions. Pirrong, supra note 238 , at $18-19,26-27$.

240 Id. at $18-19$.

241 Id. at 19.

242 Id.

243 Position portability procedures obligate surviving clearing members to assume the rights and obligations of trades entered into by defaulting clearing members. Pirrong, supra note 238.

244 See, e.g., Darrell Duffie et al., Fed. Reserve Bank of N.Y., Polrcy Perspectrves on OTC Derivatives Market Infrastructure (2010); Craig Pirrong, The Clearinghouse Cure, Regulation, Winter 2008-2009, at 44.

245 See, e.g., Sean J. Griffith, Governing Systemic Risk: Towards a Governance Structure for Derivatives Clearinghouses, 61 EMORY L.J. 1153 (2012) (analyzing clearinghouse governance and arguing in favor of the adoption of a new board structure more reflective of the public-private role of clearinghouses); Yesha Yadav, The Problematic Case of Clearinghouses in Complex Markets, 101 GEO. L.J. 387 (2013) (analyzing the CCP 
the impact of central clearing on the resolvability of derivatives counterparties, ${ }^{247}$ and the potential knock-on effects of mandatory central clearing on financial stability. ${ }^{248}$ This scholarship reflects a broad range of views regarding the desirability of mandatory central clearing of standardized derivatives. From the perspective of market efficiency, however, central clearing can be understood as holding out an important-and yet generally underappreciated-potential benefit. As we have already seen, economic and legal heterogeneity represent potentially significant obstacles to derivatives market efficiency. Central clearing can reduce this heterogeneity in three ways. First, in order to ensure that clearinghouses are able to net out the risks arising from offsetting contracts, the legal architecture supporting centrally cleared swaps must be highly standardized. ${ }^{249}$ Second, insofar as clearinghouses impose the same margin and collateral requirements on all trades in a given species of swaps, they reduce economic heterogeneity in collateral practices. ${ }^{250}$ Third, central clearing involves the novation of contracts from the original counterparties to the clearinghouse itself. In what has become one of the most repeated phrases in finance, the clearinghouse thus becomes "the buyer to every seller, and the seller to every buyer." 251 Insofar as counterparties possess any residual incentives to screen for and monitor the creditworthiness of their counterparties after the operation of closeout netting and collat-

governance structure and evaluating its ability to mitigate the risks of trading credit derivatives).

246 See, e.g., Dan Awrey, Toward a Supply-Side Theory of Financial Innovation, $41 \mathrm{~J}$. COMP. ECON. 401 (2013) (examining the incentives to curb the risks of regulatory arbitrage generated by financial innovation); Gabriel D. Rosenberg \& Jai R. Massari, Regulation Through Substitution as Policy Tool: Swap Futurization Under Dodd-Frank, 2013 Colum. Bus. L. Rev. 667 (explaining futurization with the economic model of "regulation through substitution" to address, among other things, regulatory arbitrage).

247 See Richard Squire, Clearinghouses as Liquidity Partitioning, 99 CoRnelu. L. Rev. 857 (2014) (observing that central clearing accelerates payouts to derivatives counterparties).

248 See, e.g., Mark J. Roe, Clearinghouse Overconfidence, 101 CALIF. L. REv. 1641 (2013) (assessing the value of clearinghouses in containing systemic risk); Craig Pirrong, $A$ Bill of Goods: CCPs and Systemic Risk, J. Frn. MkT. INFrastructures, June 2014, at 55 (analyzing the systemic impact of netting, collateral, and how the mandating of clearing affects interconnectedness in the financial system).

249 See Meehan \& Rosenberg, supra note 201, at 317.

250 One possible area of divergence is in the amount and quality of the collateral posted by individual counterparties. While clearinghouses will often prescribe the classes of eligible collateral, they will also typically provide counterparties with a "menu" of collateral options, thus enabling them to retain some discretion in terms of the amount and type of eligible collateral to post in satisfaction of their initial and variation margin obligations.

251 See HARris, supra note 113, at 42. A Google search of this phrase returned approximately 12,200 results. 
eral mechanisms, novation thus eliminates the need to make investments in the screening and monitoring of any counterparty other than the clearinghouse itself. In theory at least, this should serve to dramatically reduce the idiosyncratic costs of counterparty due diligence, especially where clearinghouses are required to disclose information about their capital structure, governance, and risk management policies. In effect, by reducing the noise generated by the dark side of derivatives contracts, central clearing can thus enhance the quality of the signal sent by derivatives prices. Accordingly, while the overall desirability of mandatory central clearing is still very much open to debate, ${ }^{252}$ increasing the proportion of derivatives trades routed through clearinghouses may have a positive impact on market efficiency.

The prospective benefits of central clearing associated with greater legal and economic homogeneity also point to at least two potentially significant limits. First, insofar as the regulation of clearinghouses diverges across jurisdictions, legal and economic heterogeneity will continue to exist within centrally-cleared derivatives markets. In theory, the leaders of the G20 group of countries have publicly committed to mandatory central clearing of standardized derivatives. ${ }^{253}$ In practice, however, significant areas of divergence can be observed in the design and implementation of the relevant regulatory reforms. Yesha Yadav and Dermot Turing, for example, have identified divergence between the Dodd-Frank Act and EMIR regimes governing clearinghouses across a number of important dimensions, from margin and collateral requirements, default fund and waterfall mechanisms, and clearinghouse governance and risk management, to supervisory oversight, stress testing, and access to central bank emergency liquidity assistance. ${ }^{254}$ Second, insofar as many of the new regulatory reforms targeting clearinghouses are framed as minimum standards, there is scope for clearinghouses to respond to competitive pressures by attempting to differentiate themselves on the basis of non-price terms such as the amount or quality of required collateral. Ultimately, the resulting heterogeneity may serve to undercut the potential benefits of central clearing from the perspective of market efficiency.

252 See supra notes $244-48$.

253 U.S. Dep't of the Treasury, Leaders' Statement: The Prtrsburgh Summit 9 (Sept. 24-25 2009), https://www.treasury.gov/resource-center/international/g7-g20/ Documents/pittsburgh_summit_leaders_statement_250909.pdf.

254 Yesha Yadav \& Dermot Turing, The Extraterritorial Regulation of Clearinghouses, 2 J. Fin. REG. 21, 41 (2016). 


\section{Prudential Regulation of Derivatives Dealers}

In addition to enhancing the transparency of derivatives markets and introducing mandatory central clearing for many standardized derivatives, post-crisis regulatory reforms have also targeted the prudential regulation of derivatives dealers. The majority of these reforms have been spearheaded by the Basel Committee on Banking Supervision (BCBS) as part of its comprehensive amendments to its international framework for the regulation, supervision, and risk management of banks, more commonly known as "Basel III." Basel III refines the definition of capital for regulatory purposes, increases the percentage of common equity tier-1 (CET1) capital that banks are required to hold against risk-weighted assets, modifies the framework for calculating the risk weightings applied to various asset classes, and introduces a series of new capital buffers designed to reduce the procyclicality of capital requirements, constrain excessive lending during periods of economic growth, and eliminate the "too-big-to-fail" subsidy. ${ }^{255}$ Basel III also introduces a new maximum leverage ratio based on non-risk weighted assets, ${ }^{256}$ along with two new liquidity requirements: the Liquidity Coverage Ratio (LCR) ${ }^{257}$ and Net Stable Funding Ratio (NSFR). ${ }^{258}$ The LCR is designed to ensure that banks have a sufficient stock of high-quality liquid assets to survive a hypothetical thirty-day stress scenario. The NSFR is designed to constrain the reliance of banks on unstable, short-term sources of wholesale funding. ${ }^{259}$

255 For more detailed information about the Basel III capital framework, see BASEI Comm. on Banking Supervision, Bank for Int'l Settlements, Basel III: A Global Regulatory Framework for More Resilient Banks and Banking Systems (2011), http://www.bis.org/publ/bcbs189.htm. For further information about the progress of Basel III implementation in the United States, see Basel Regulatory Framework, BD. GOVERNORS FOR FED. RESERVE SYS., http://www.federalreserve.gov/bankinforeg/basel/ USImplementation.htm (last visited July 17, 2016). See also Regulatory Capital Rules: Regulatory Capital, Implementation of Basel III, Capital Adequacy, Transition Provisions, Prompt Corrective Action, Standardized Approach for Risk-Weighted Assets, Market Discipline and Disclosure Requirements, Advanced Approaches Risk-Based Capital Rule, and Market Risk Capital Rule, 78 Fed. Reg. 62,018 (Oct. 11, 2013) (codified at 12 C.F.R. pts. 208, 217 \& 225) [hereinafter U.S. Final Capital Rule].

256 Basel Comm. on Banking Supervision, Bank for Int'l Settlements, Basel III Leverage Ratio Framework and Disclosure Requirements (2014), http://www.bis. org/publ/bcbs270.htm.

257 Basel Comm. on Banking Supervision, Bank for Int'l. Settlements, Basel III: The Liquidity Coverage Ratio and LIquidity Risk Monitoring Tools (2013), http://www.bis.org/publ/bcbs238.htm.

258 Basel Comm. on Banking Supervision, Bank for Int'l Settlements, Basel III: The Net Stable Funding Ratio (2014), http://www.bis.org/bcbs/publ/d295.htm.

259 Id. 
Basel III introduces a number of significant changes to the framework for calculating risk-weightings for capital charges in connection with both bilaterally and centrally-cleared derivatives trades. ${ }^{260}$ For bilaterally-cleared derivatives, Basel III augments the existing framework governing the amount of capital that banks must hold against counterparty credit risk with a new credit valuation adjustment (CVA). ${ }^{261}$ Whereas the previous framework essentially only required banks to hold sufficient capital to cover losses stemming from counterparty default, the CVA is designed to ensure that banks hold sufficient capital to protect against any mark-to-market losses stemming from the deterioration of a counterparty's creditworthiness over the life of a derivatives contract. ${ }^{262}$ The introduction of the CVA is a reflection of the fact that, during the recent crisis, approximately twothirds of realized losses experienced by banks on their derivatives portfolios were attributable to the deterioration of counterparty credit quality as opposed to actual counterparty default. ${ }^{263}$ Importantly, the introduction of the CVA has coincided in the U.S. with the removal of what was previously a fifty percent ceiling on the risk weights applied to derivatives exposures. ${ }^{264}$

Basel III also introduces a new risk-weighting framework for centrally cleared derivatives. First, where a bank enters into a derivatives trade for its own purposes, Basel III imposes a relatively modest capital charge equal to two percent of the resulting trade exposure to any qualifying clearinghouse. ${ }^{265}$ A qualifying clearinghouse for these purposes is effectively one that complies with the CPMI-IOSCO

260 Capital requirements mandate a specified percentage of a bank's financing-relative to its assets - that must be in the form of equity and other forms of "regulatory" capital. The assets on which these capital requirements are based are then subject to risk weighting, with the objective of ensuring that as a bank invests in riskier assets it will be required to finance itself using a higher proportion of equity and other forms of regulatory capital. See generally ARMOUR ET AL., supra note 164 (manuscript at 290-315).

261 See Basel Comm. on Banking Supervision, Bank for InT'L Settlements, supra note 255, at 3; see also U.S. Final Capital Rule, supra note 255 (describing the increased capital requirements under the new CVA requirements).

262 Basel Comm. on Banking Supervision, Bank for Int'l Settlements, supra note 255, at 3; see also BAsel COMm. ON BANKIng SUPERvision, BANK FOr INT'L Settlements, Regulatory Reform of Over-the-Counter Derivatives: An Assessment of InCENTIVes to Clear CENTRally 4 (2014), http:/www.bis.org/publ/ othp21.htm ("[T]he CVA capital charge addresses the potential mark-to-market loss caused by an increase in the credit spread of the counterparty.").

263 U.S. Final Capital Rule, supra note 255, at 62,134.

264 Id. at 62,096; see also U.S. Basel III Final Rule: Standardized Risk Weights Tool, Davis Polk, http:/www.usbasel3.com/tool/ (last visited July 17, 2016).

265 Basel Comm. on Banking Supervision, Bank for Int'l Setrlements, CaptTal Requirements for Bank Exposures to Central Counterparties 4-5 (2012), http:/ www.bis.org/publ/bcbs227.pdf. The two percent risk weighting against trade exposures to clearinghouses also applies where a bank clears trades on behalf of its clients, but only 
Principles for Financial Market Infrastructures. ${ }^{266}$ In contrast, the equivalent risk weightings for trades cleared through non-qualifying clearinghouses range from twenty to one hundred percent depending on the identity of the clearinghouse. ${ }^{267}$ Second, Basel III imposes a capital charge on clearing members on the basis of their exposure to a clearinghouse's default fund. ${ }^{268}$ As described above, in order to mutualize any residual losses stemming from the default of a clearing member, clearinghouses typically require members to contribute to a default fund that can be drawn down in the event that any other member defaults on its obligations and the resulting losses to the clearinghouse exceed both the posted margin and default fund contribution of the defaulting member. ${ }^{269}$ While the new trade exposure charge is designed to ensure that a bank has sufficient capital to cover losses arising from its direct exposure to a clearinghouse, the new default fund exposure charge can thus be understood as designed to ensure that banks hold sufficient capital against their indirect exposure to the default of other clearing members.

Amongst the many ways that banks can soften the impact of the Basel III capital requirements is the utilization of credit risk mitigation techniques such as collateralization: the posting of initial and variation margin. For example, by ensuring that their derivatives trade exposures are sufficiently collateralized by high quality liquid assets, counterparties can reduce the amount of capital they are required to hold against counterparty credit risk. ${ }^{270}$ Against this backdrop, policymakers have recently introduced a number of regulatory reforms that can be expected to have an impact on both the supply and demand for eligible collateral. First, the BCBS and International Organization of Securities Commission (IOSCO) have introduced a new framework imposing more onerous margin requirements on bilaterally cleared derivatives. ${ }^{271}$ This framework articulates baseline minimum amounts

where the bank also guarantees the client against any losses stemming from the failure of the relevant clearinghouse. Id. at 6 .

$266 \mathrm{Id}$. at 2. For further details, see Comm. Payment \& Settlement Systems, Bank for Int'L Settlements, Principles for Financial. Market Infrastructures (2012), $\mathrm{http} / / / \mathrm{www}$. bis.org/cpmi/publ/d101a.pdf. Ultimately, one could ask whether these principles are sufficiently detailed to make any assessment of "compliance" truly meaningful.

267 Basel Comm. on Banking Supervision, Bank for Int'l Settlements, supra note 265 , at 7 n. 12 .

268 Id. at $7-10$.

269 See supra Section IV.C (describing the elements of a clearinghouse's capital waterfall).

270 For further information, see Comm. PAyment \& Sertlement Systems, Bank for INT'L SETTLEMENTS, supra note 266, at 26-47.

271 Basel Comm. on Banking Supervision, Bank for InT'l Settlements \& INT'l Org. of Sec. Comm'ns, Margin Requirements for Non-Centrally Cleared 
and methodologies for calculating initial and variation margin, ${ }^{272}$ requires the bilateral exchange of both initial and daily variation margin on a gross basis, ${ }^{273}$ provides guidance regarding the definition of eligible collateral and collateral haircuts, ${ }^{274}$ and prescribes the use of collateral holding models that ensure the collateral is immediately available to the collateral taker in the event of default. ${ }^{275}$ Second, the push toward mandatory central clearing-and with it daily mark-tomarket margining by clearinghouses-will mean that clearing members must be prepared to post high-quality liquid assets on short notice in satisfaction of variation margin requirements. In order to satisfy these requirements, along with the new LCR, it is likely that clearing members will be compelled to hold a higher proportion of eligible collateral assets on their balance sheets. Finally, the Financial Stability Board (FSB) has proposed restrictions on the ability of dealers and other market participants to reuse or rehypothecate collateral posted in connection with repurchase agreements, securities lending transactions, or the provision of prime brokerage services. 276 If adopted, these restrictions will limit the ability of dealers to use posted collateral for the purpose of financing their proprietary trading activities. ${ }^{277}$ In the aggregate, these reforms seem likely to increase the demand for high-quality liquid collateral assets, and thus also increase the cost of collateralizing derivatives trades. What is more, they will be doing so at precisely the same time that new capital requirements are incentivizing greater collateralization of derivatives trades. ${ }^{278}$

Derivatives (2015), http://www.bis.org/publ/bcbs261.pdf [hereinafter BIS/IOSCO MARgin ReQuirements]. These rules have recently been incorporated into U.S. law. Margin and Capital Requirements for Covered Swap Entities, 80 Fed. Reg. 74,840 (Nov. 30, 2015) (codified at 12 C.F.R. pts. 45, 237, 349, 624 \& 1221); Margin Requirements for Uncleared Swaps for Swap Dealers and Major Swap Participants, 81 Fed. Reg. 636 (Jan. 6, 2016) (codified at 17 C.F.R. pts. $23 \& 140$ ). The SEC is expected to adopt equivalent rules in the near future.

272 BIS/IOSCO MARGIN REQUIREMENTs, supra note 271, at 10-16.

273 Id. at 9.

274 Id. at $16-18,26$.

$275 \mathrm{Id}$. at 18-21.

276 Fin. Stability Bd., Strengthening Oversight and Regulation of Shadow Banking: Policy Framework for Strengthening Oversight and Regulation of SHADOW BANKING ENTITIEs (2013), www.financialstabilityboard.org/wp-content/uploads/ r_130829b.pdf?page_moved $=1$.

277 See id. at 16.

278 The cost of collateral can be understood as the difference between the cost of funding the acquisition and holding of the collateral and the return generated on the collateral. Viewed from this perspective, it is effectively the opportunity cost of holding collateral versus other assets. 
Together with other recent regulatory reforms targeting derivatives markets, these new capital, liquidity, and collateral requirements will almost inevitably increase the costs of market making for derivatives dealers. Global consulting firm McKinsey \& Company has estimated that the new capital requirements introduced under Basel III will increase costs by an average of eighty-five basis points $(0.85$ percent) for unnetted, uncollateralized derivatives trades. ${ }^{279}$ Compounding these costs, Manmohan Singh has estimated that the shift toward mandatory central clearing may require up to US $\$ 200$ billion in additional initial margin. ${ }^{280}$ The BCBS and IOSCO, meanwhile, have estimated that between $€ 700$ billion and $€ 1.7$ trillion in initial margin will be required to collateralize bilaterally-cleared derivatives trades. ${ }^{281}$ The BCBS has also estimated that the new LCR will increase demand for high-quality liquid assets by approximately $€ 1.8$ trillion. ${ }^{282}$

Ultimately, of course, it is difficult to quantify the marginal costs of these reforms with any real precision. It is equally difficult to predict how dealers will respond to them. Nevertheless, a number of industry observers have predicted that dealers may respond by withdrawing from market making in connection with many lower margin derivatives contracts. ${ }^{283}$ The probability of such a withdrawal has no doubt increased following the implementation of the so-called

279 Philipp Härle et al., Basel III and European Banking: Its Impact, How Banks Might Respond, and the Challenges of Implementation 9-11 (McKinsey, Working Papers on Risk No. 26, Nov. 2010), http://www.mckinsey.com/business-functions/risk/our-insights/basel-iiiand-european-banking.

280 Manmohan Singh, Collateral, Netting and Systemic Risk in the OTC Derivatives Markets 10 (Int'l Monetary Fund, Working Paper No. 10/99, 2010), http://www.imf.org/ external/pubs/ft/wp/2010/wp1099.pdf.

281 Basel Comm. on Banking Supervision, Bank for Int'L Settlements \& Int'L Org. of Sec. Comm'ns, Margin Requirements for Non-Centrally Cleared Derivatives, Consultative Document (2012), http://www.bis.org/publ/bcbs226.pdf; Basel Comm. on Banking Supervision, Bank for Int'l Settlements \& INT'L Org. of Sec. Comm'ns, Margin Reguirements for Non-Centrally Cleared Derivatives, Second Consultative Document (2013) at 33, http://www.bis.org/publ/ bcbs242.pdf.

282 Basel Comm. on Banking Supervision, Bank for Int'l Settlements \& Int'L Org. OF Sec. Comm'ns, Results of the Basel III Monitoring Exercise as of 30 JUNE 2011 (2012), at 3, 18, 20, http://www.bis.org/publ/bcbs217.pdf; BASEL COMM. ON Banking Supervision, Bank for INT'L SetTlements \& Int'L Org. Of Sec. Comm'ns, Basel III: International Framework for Liquidity Risk Measurement, STANDARDS AND MONITORING (2010), http://www.bis.org/publ/bcbs188.pdf (discussing the possible shortage of high quality assets).

283 See, e.g., Delortre, OtC Derivatives: The New Cost of Trading 2 (2014), http://www2.deloitte.com/content/dam/Deloitte/uk/Documents/financial-services/deloitteuk-fs-otc-derivatives-april-14.pdf (predicting that dealer banks may withdraw from asset classes "deemed to be too costly"). 
"Volcker Rule,"284 which severely limits the ability of dealer banks to engage in proprietary trading alongside their market-making activities-thus eliminating one of the means by which dealers might seek to monetize the informational advantages they enjoy by virtue of their role as structurally informed traders. ${ }^{285}$ Most importantly for the present purposes, should these reforms precipitate such a correlated withdrawal, this would seem highly likely to have an adverse impact on market liquidity and, with it, informational efficiency. This serves to highlight a potential tradeoff between the prudential regulation of derivatives dealers and the incentives of these structurally-informed traders to perform their vital market-making role.

\section{E. The Optimal Balance Between Private Ordering and Public Regulation}

A good deal of scholarship has already been written examining the optimal balance between private ordering and public regulation within derivatives markets. ${ }^{286}$ As we have seen, private actors such as dealers, interdealer brokers, ECNs, and ISDA have each played a significant role in the emergence, development, and ongoing evolution of derivatives markets. At the same time, however, and as we might expect, these private actors do not always possess the strongest incentives to respond to the myriad of information, agency, and other

284 Dodd-Frank Wall Street Reform and Consumer Protection Act, Pub. L. No. 111-203, $\S 619,124$ Stat. 1376,1620 (2010).

285 For an overview of how the Volcker Rule could serve to reduce liquidity within derivatives and other markets, see Darrell Duffie, Market Making Under the Proposed Volcker Rule (Rock Ctr. for Corp. Governance, Working Paper No. 106, 2012), http:// papers.ssrn.com/sol3/papers.cfm?abstract_id=1990472.

286 See, e.g., Dan Awrey, The Dynamics of OTC Derivatives Regulation: Bridging the Public-Private Divide, 11 Eur. Bus. Org. L. Rev. 155 (2010) (exploring public and private systems of ordering and ultimately endorsing modes that abandon this distinction); Sean M. Flanagan, The Rise of a Trade Association: Group Interactions Within the International Swaps and Derivatives Association, 6 Harv. Negot. L. Rev. 211 (2001) (describing the functions and strengths of the ISDA as a trade association for individuals involved with over-the-counter derivatives markets); John T. Lynch, Comment, Credit Derivatives: Industry Initiative Supplants Need for Direct Regulatory Intervention-A Model for the Future of U.S. Regulation?, 55 BUFF. L. REv. 1371 (2008) (describing the success of the private sector initiatives to address problems in the credit derivatives market and proposing a shift toward self-regulation of these markets); Brian J.M. Quinn, The Failure of Private Ordering and the Financial Crisis of 2008, 5 N.Y.U. J.L. \& Bus. 549 (2009) (arguing that private ordering has failed to adequately address market failures and endorsing specific regulatory measures as a means of producing desired outcomes); Lynn A. Stout, Why the Law Hates Speculators: Regulation and Private Ordering in the Market for OTC Derivatives, 48 DUKE L.J. 701 (1999) (describing a hybrid model of regulation as an alternative to the binary options of regulation and exemption and the benefits of such a model). 
problems encountered within these markets. ${ }^{287}$ Dealers, for example, have sometimes abused their market power and position as structurally-informed traders to exploit financially unsophisticated clients. ${ }^{288}$ And while hard data is scarce, it is likely that a significant fraction of historical derivatives trading activity has been significantly undercollateralized, thereby generating risks to both institutional and broader financial stability. ${ }^{289}$ In theory, the failure of private actors to effectively respond to these problems opens a window for public regulatory intervention-a window that policymakers have been quick to jump through in the wake of the financial crisis. Ideally, however, this impulse should be constrained in favor of a more rigorous examination of the feasibility, potential costs and benefits, and likely behavioral impact of public regulatory intervention. 290

Our examination of the mechanisms of derivatives market efficiency holds out a number of potentially useful insights into important policy issues at the intersection of private ordering and public regulation. This section briefly examines two of these issues. The first stems from recent proposals to supplement or replace conventional capital requirements for banks with more market-based indicators of institutional stability. Oliver Hart and Luigi Zingales, for example, have advanced a proposal that would replace capital requirements for systemically important banks with prudential requirements based on these banks' CDS prices. ${ }^{291}$ Under Hart and Zingales's proposal, where CDS spreads on a bank's junior term debt exceed specified thresholds, this would trigger a requirement for the bank to raise additional equity or enable prudential supervisors to take other remedial measures. ${ }^{292}$ In effect, this proposal seeks to harness the perceived informational efficiency of CDS markets to negative credit information in order to create an "early warning system" 293 alerting regulators to potential institutional instability.

287 See Awrey, supra note 116, at 190-200 (describing the positive network externalities, path dependency, and power imbalances that impede the efficient emergence, development, and evolution of systems of private ordering).

288 See, e.g., Interest Rate Hedging Products (IRHP), supra note 119 (detailing recent UK swaps mis-selling scandal).

289 See Manmohan Singh, Under-Collateralisation and Rehypothecation in the OTC Derivatives Markets, Banoue de France Fin. Stability Rev., July 2010, at 113, 114.

290 This approach is reflected in Ronald Coase's statement that "[s]atisfactory views on policy can only come from a patient study of how, in practice, the market, firms, and governments handle the problem of harmful effects." R.H. Coase, The Problem of Social Cost, 3 J.L. \& Econ. 1, 18 (1960).

291 See Hart \& Zingales, supra note 83.

292 Id. at 453.

293 Id. at 455. 
The desirability of Hart and Zingales's proposal is contingent on the quality of the signal sent by CDS prices. ${ }^{294}$ As we have already observed, however, this signal may be vulnerable to distortions stemming from idiosyncratic counterparty credit risk, along with other potential sources of legal and economic heterogeneity. CDS prices may also be distorted by the simultaneous withdrawal of liquidity by dealers and other market participants during periods of broader market disruption. During periods of market disruption, an observed increase in CDS spreads may therefore reflect a systemic adverse selection problem of the variety observed in connection with the recent crisis as opposed to the market's assessment of the creditworthiness of individual banks. This puts prudential supervisors in the difficult position of having to distinguish between those banks that actually require recapitalization in order to avoid potential solvency problems, and those that-while also caught up in the systemwide adverse selection problem - are otherwise fundamentally sound. Out of an abundance of caution, supervisors might reasonably elect under these circumstances to require all systemically important banks to raise fresh capital, 295 thus essentially negating the primary benefit of this more market-based approach toward capital requirements.

As we have seen, part of the solution to this problem is to subject the CDS contracts upon which Hart and Zingales's proposal relies to mandatory central clearing. This would eliminate the distortions generated by idiosyncratic counterparty credit risk, if not those stemming from any deterioration in the creditworthiness of the relevant clearinghouse. These CDS should also be subject to mandatory exchange trading, ${ }^{296}$ thereby ensuring the existence of at least one source of market liquidity that is at least theoretically independent of the willingness of dealers to make markets in these contracts. ${ }^{297}$ Ultimately, however, even these relatively interventionist measures cannot completely eliminate the possibility that bank CDS prices may

294 Hart and Zingales do contemplate that prudential supervisors will conduct a stress test on the relevant bank for the purposes of determining whether CDS prices are accurate. $I d$. at 457 . Even here, however, there are important questions surrounding the feasibility of conducting these tests on multiple banks, and within a relatively short timespan, in the context of an unfolding crisis.

295 As the U.S. federal government arguably did in the fall of 2008 when it required many of its largest and most interconnected banks to issue new preferred shares and warrants pursuant to the Capital Purchase Program under the Troubled Asset Relief Program.

296 Id. at 466 . While Hart and Zingales do suggest that the relevant CDS contracts should be traded on exchanges, they do not provide an explicit rationale for this suggestion.

297 In practice, of course, dealers might also represent significant sources of liquidity as both buyers and sellers within exchange-traded derivatives markets. 
be the least informative at the precise moment at which this information is most urgently required.

The prospect that dealers might withdraw from derivatives market-making has a second potential implication in terms of the optimal balance between public and private ordering. Given the structure of derivatives markets, we would expect the correlated withdrawal of liquidity by dealers to have a significant impact on market efficiency. Insofar as well-functioning derivatives markets are essential to effective risk management by banks and other financial institutions, the withdrawal of liquidity might also be expected to have an adverse impact on financial stability. Against this backdrop, the threat of withdrawal can be understood as giving dealers powerful leverage over elected officials, regulatory authorities, and financial supervisors who understandably do not want to be perceived as adopting policies-for example, capital, liquidity, collateral, or other requirements-that threaten to undermine market efficiency or stability. It is not inconceivable that dealers would then wield this leverage in order to lobby for the adoption of regulatory requirements that do not impose significant costs or which entrench their position as structurally-informed traders. Viewed from this perspective, the dealer-intermediated structure of derivatives markets thus exacerbates the already acute political economy problems that often undermine the pursuit of effective financial regulation.

One way that policymakers can potentially dilute the potency of this threat is by taking a more proactive approach toward the development of alternative sources of market liquidity. One possible option would be to compel derivatives exchanges to make derivatives instruments deemed to have some degree of systemic importance available for trading as a condition of their registration. Instruments falling into this category might include, for example, certain highly liquid interest rate and currency derivatives, or the CDS written on the debt of systemically important banks envisioned by Hart and Zingales's proposal. In exchange, regulators could provide derivatives exchanges with subsidized liquidity support or loss mutualization mechanisms in connection with trading in these instruments.

A second and more radical option would be for central banks such as the U.S. Federal Reserve System to play a more active role in derivatives market-making. Indeed, in many respects, central bankswith their vast networks of member banks, large balance sheets, and the effective absence of counterparty credit risk-are almost the ideal market makers. Thus, for example, and putting aside the fact that this would likely require significant changes to the scope of its authority 
under the Federal Reserve Act, ${ }^{298}$ the Fed could publish firm quotes on systemically important derivatives instruments. Under normal market conditions, these quotes could be set just outside the prevailing bid and asking prices quoted by private dealers, thereby minimizing any market distortions stemming from the Fed's presence in the market. At the same time, this presence would offer a credible alternative for those not wanting to transact with private dealers, or in the event of the widespread withdrawal of private liquidity. In effect, this option would institutionalize what Perry Mehrling has described as the Fed's "dealer of last resort" function in the context of both the recent and previous financial crises. ${ }^{299}$

While this option might at first glance seem like a dramatic expansion of the role of the state within ostensibly private markets, it is worth making three preliminary observations. First, as illustrated by large-scale interventions of the U.S. Treasury and Federal Reserve during the recent crisis, states already perform this role during periods of systemic instability. What is more, formalizing this role along with the credible threat of ex post sanctions-for example compensation clawbacks and personal liability for officers and directors-could help constrain the moral hazard associated with the near inevitability of state intervention in these circumstances. ${ }^{300}$ Second, states arguably possess a comparative advantage over private derivatives dealers in terms of their ability to make markets in derivatives. Specifically, the size of their balance sheets, the absence of binding solvency or liquidity constraints, and the legal authority to print money puts states in an advantageous position to provide the missing markets for liquidity during periods of financial instability. The state is thus able to provide credible insurance against systemic replacement risk. Finally, a well-designed dealer of last resort mechanism presents something of a "win-win" proposition. If the threat of correlated dealer withdrawal or failure is credible, the dealer of last resort mechanism can play an important role in stabilizing derivatives markets. Meanwhile, if the threat is not credible, the distortions generated by state intervention into private markets are likely to be minimal as relatively few, if any, market participants will take advantage of this mechanism.

The objective in identifying these possible options is not to put them forward as optimal strategies for reducing the political economy

298 Federal Reserve Act, ch. 6, 38 Stat. 251 (codified as amended in scattered sections of 12 U.S.C.).

299 See MenrLING, supra note 139, at 132.

300 For a compelling argument in favor of the imposition of these mechanisms (and in particular personal liability for officers and directors), see John Armour \& Jeffrey N. Gordon, Systemic Harms and Shareholder Value, $6 \mathrm{~J}$. Legal Analysis 35, $61-76$ (2014). 
and other problems stemming from the dealer-intermediated structure of derivatives markets. Indeed, these options raise important theoretical and practical questions in terms of their design, implementation, and potential costs. A comprehensive exploration of these options and questions resides beyond the scope of this Article. What identifying these options does do, however, is illustrate how understanding the structure of derivatives markets-and the mechanisms of derivatives market efficiency-can help us better frame these important policy problems and identify potential strategies for tackling them.

\section{CONCLUSION}

Derivatives are different. These differences stem from the executory nature of derivatives contracts, the dealer-intermediated structure of the markets in which they trade, and the role of derivatives dealers as the primary sources of market liquidity. These differences generate information, agency, coordination, and other problems not generally encountered within public equity markets. These problems have led to the emergence of a unique constellation of institutional arrangements that-in theory at least-serve to promote derivatives market efficiency. To date, however, the contribution of these mechanisms toward derivatives market efficiency has received surprisingly little attention from scholars or policymakers. Reflecting this gap in our understanding, the role and importance of these mechanisms has not featured prominently in recent policy debates examining the impact of post-crisis regulatory reforms targeting derivatives markets. The objective of this Article has been to close this gap.

Ultimately, perhaps the most important contribution of this Article is to identify avenues for further theoretical and empirical research. As a preliminary matter, there is still a paucity of empirical research examining how (and how quickly) derivatives markets other than those for CDS impact new information into prices. Given the potentially significant differences in terms of the information sensitivity of the underlying assets, the ability of traders to identify traders with superior information, and other factors, we must be careful not to extrapolate too far on the basis of existing evidence. Second, there is still much to learn about the more granular operation of the mechanisms of derivatives market efficiency. How much information do traders actually glean off the trading activities of derivatives dealers? From interdealer brokers and ECNs? And how-if at all-do traders take into account the economic and legal heterogeneity of derivatives contracts in the process of determining prices? Third, we are still largely in the dark about the dark side of derivatives markets. How 
well are derivatives markets collateralized? How heterogeneous are the contractual terms surrounding, for example, variation margin triggers? And how do these terms differ between bilateral and centrally cleared markets, and across jurisdictions? Finally, we still have a long way to go to understand the impact of recent regulatory reforms on derivatives trade volumes, market structure and liquidity, and informational efficiency. The answers to these questions are vital if we are to better understand the role derivatives play in modern financial markets and how best to approach their regulation. 
APPENDIX

\begin{tabular}{|c|c|}
\hline Contractual Data Point & Reported As \\
\hline \multicolumn{2}{|l|}{ Applicable Law } \\
\hline $\begin{array}{l}\text { 1. The jurisdiction of the law governing the } \\
\text { contract (typically New York or the UK). }\end{array}$ & [e.g., NY] \\
\hline $\begin{array}{l}\text { 2. The jurisdiction of incorporation of each of } \\
\text { the counterparties (for the purposes of } \\
\text { determining relevant contract, property, and } \\
\text { insolvency rules). }\end{array}$ & [e.g., NY, UK] \\
\hline \multicolumn{2}{|l|}{ Assignment } \\
\hline $\begin{array}{l}\text { 3. Whether the contract is assignable by one or } \\
\text { both parties (for the purposes of determining } \\
\text { whether counterparties may "run by } \\
\text { assignment" as took place in the case of Bear } \\
\text { Stearns. This information also ties in with data } \\
\text { point } 9 \text { below as the ability of a counterparty to } \\
\text { return any pledged collateral upon assignment } \\
\text { will be a function of whether it has reused or } \\
\text { rehypothecated this collateral). }\end{array}$ & {$[\mathrm{Y} / \mathrm{N}]$} \\
\hline \multicolumn{2}{|l|}{ Closeout Netting } \\
\hline $\begin{array}{l}\text { 4. Whether the contract is subject to standard } \\
\text { ISDA provisions in relation to closeout netting } \\
\text { (for the purpose of calculating net cash flows } \\
\text { upon default-assuming information about } \\
\text { other relevant exposures is available). }\end{array}$ & {$[\mathrm{Y} / \mathrm{N}]$} \\
\hline \multicolumn{2}{|l|}{ Collateralization } \\
\hline $\begin{array}{l}\text { 5. Whether the collateral is posted pursuant to } \\
\text { a title transfer or security interest system. }\end{array}$ & [TT/SI] \\
\hline $\begin{array}{l}\text { 6. Whether one or both counterparties are } \\
\text { required to post an initial amount (IA) at the } \\
\text { outset of a contract (this information would } \\
\text { ideally be supplemented by information about } \\
\text { the amount and quality of pledged collateral, } \\
\text { along with the historical correlation between } \\
\text { the collateral assets and underlying). }\end{array}$ & {$[\mathrm{Y} / \mathrm{N}]$} \\
\hline
\end{tabular}




\begin{tabular}{|l|c|}
\hline $\begin{array}{l}\text { 7. Whether one or both counterparties are } \\
\text { required to post variation margin (VM) over } \\
\text { the duration of the contract (again, this } \\
\text { information would ideally be supplemented by } \\
\text { information about the amount, quality, and } \\
\text { correlations of pledged collateral -if specified } \\
\text { ex ante). }\end{array}$ & [Y/N] \\
\hline $\begin{array}{l}\text { 8. The timing for the calculation and delivery of } \\
\text { VM (e.g., daily, weekly, quarterly, etc.). }\end{array}$ & [D/W/Q] \\
\hline $\begin{array}{l}\text { 9. Any triggering events which have the effect of } \\
\text { obligating a party to post VM-e.g., changes in } \\
\text { the market value of the underlying or } \\
\text { downgrades in the credit rating of either a } \\
\text { counterparty or, in the case of credit } \\
\text { derivatives, underlying reference entities or } \\
\text { obligations (for the purpose of determining } \\
\text { whether a counterparty may be subject to } \\
\text { procyclical collateral calls as took place in the } \\
\text { case of AIG Financial Products). }\end{array}$ & $\begin{array}{l}\text { [e.g., CR } \\
\text { downgrade] }\end{array}$ \\
\hline $\begin{array}{l}\text { 10. Whether one or both parties have permitted } \\
\text { the reuse or rehypothecation of pledged } \\
\text { collateral (this information ties in with points 1 } \\
\text { and } 2 \text { above as the treatment of pledged } \\
\text { collateral varies by jurisdiction). }\end{array}$ & \begin{tabular}{l} 
[Y/N] \\
\hline $\begin{array}{l}\text { 11. Measures of the composition of posted } \\
\text { collateral. }\end{array}$
\end{tabular} \\
\hline $\begin{array}{l}\text { 12. Measures of the quality of posted collateral. } \\
\text { [e.g., percentage of } \\
\text { different asset } \\
\text { classes] }\end{array}$ \\
$\begin{array}{l}\text { [e.g., collateral } \\
\text { baskets used by } \\
\text { central banks in } \\
\text { connection with } \\
\text { access to the } \\
\text { discount window] }\end{array}$ \\
\hline
\end{tabular}

